\title{
Time-resolved measurements of black carbon light absorption enhancement in urban and near-urban locations of southern Ontario, Canada
}

\author{
T. W. Chan ${ }^{1}$, J. R. Brook ${ }^{2}$, G. J. Smallwood ${ }^{3}$, and G. Lu $^{2}$ \\ ${ }^{1}$ ASTB/STB Environment Canada, 335 River Road South, Ottawa, Ontario, K1V 0H3, Canada \\ ${ }^{2}$ ASTB/STB Environment Canada, 4905 Dufferin Street, Toronto, Ontario, M3H 5T4, Canada \\ ${ }^{3}$ National Research Council Canada, 1200 Montreal Road, Ottawa, Ontario, K1A 0R6, Canada
}

Received: 13 August 2010 - Published in Atmos. Chem. Phys. Discuss.: 24 August 2010

Revised: 17 September 2011 - Accepted: 6 October 2011 - Published: 20 October 2011

\begin{abstract}
In this study a photoacoustic spectrometer (PA), a laser-induced incandescence instrument system (LII) and an Aerosol Mass Spectrometer were operated in parallel for in-situ measurements of black carbon (BC) light absorption enhancement. Results of a thermodenuder experiment using ambient particles in Toronto are presented first to show that LII measurements of BC are not influenced by the presence of non-refractory material thus providing true atmospheric BC mass concentrations. In contrast, the PA response is enhanced when the non-refractory material is internally mixed with the $\mathrm{BC}$ particles. Through concurrent measurements using the LII and PA the specific absorption cross-section (SAC) can be quantified with high time resolution (1 min). Comparisons of ambient PA and LII measurements from four different locations (suburban Toronto; a street canyon with diesel bus traffic in Ottawa; adjacent to a commuter highway in Ottawa and; regional background air in and around Windsor, Ontario), show that different impacts from emission sources and/or atmospheric processes result in different particle light absorption enhancements and hence variations in the SAC. The diversity of measurements obtained, including those with the thermodenuder, demonstrated that it is possible to identify measurements where the presence of externally-mixed non-refractory particles obscures direct observation of the effect of coating material on the SAC, thus allowing this effect to be measured with more confidence. Depending upon the time and location of measurement (urban, rural, close to and within a lake breeze frontal zone), $30 \mathrm{~min}$ average SAC varies between $9 \pm 2$ and $43 \pm 4 \mathrm{~m}^{2} \mathrm{~g}^{-1}$. Causes of this variation, which were
\end{abstract}

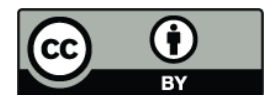

Correspondence to: T. W. Chan (tak.chan@ec.gc.ca) determined through the use of meteorological and gaseous measurements $\left(\mathrm{CO}, \mathrm{SO}_{2}, \mathrm{O}_{3}\right)$, include the particle emission source, airmass source region, the degree of atmospheric processing. Observations from this study also show that the active surface area of the $\mathrm{BC}$ aggregate, which is measured by the LII as the PPS, is an important parameter for inferring the degree of particle collapse of a BC particle. In addition, PPS could be a useful measurement for indicating the importance of recently emitted $\mathrm{BC}$ (e.g. from gasoline or diesel engines) relative to the total measured $\mathrm{BC}$ in the atmosphere.

\section{Introduction}

Black carbon (BC) particles are released into the atmosphere from incomplete combustion of fossil and biofuels, and biomass burning (Horvath, 1993). In engines, BC particles are formed during combustion at temperatures between about 1000 and $2800 \mathrm{~K}$, at pressures of 50 to $100 \mathrm{~atm}$ inside both gasoline and diesel powered engines, with higher concentrations from the latter (Heywood, 1988). The BC formation and oxidation processes are completed before the exhaust exits the combustion engine. The $\mathrm{BC}$ formation process can be summarized by a series of steps with an initial nucleation process to produce the $\mathrm{BC}$ precursors, followed by a vapour to particle surface growth process to form the $\mathrm{BC}$ spherules up to about 10 to $30 \mathrm{~nm}$, and then by the agglomeration process, which leads to the formation of chainlike and aggregate structures (Amann and Siegla, 1982; Heywood, 1988).

Based on different definitions and methods of detection, $\mathrm{BC}$ is sometimes referred to as "refractory carbon" or "elemental carbon", representing the solid carbon fraction in the

Published by Copernicus Publications on behalf of the European Geosciences Union. 
particles, with a high sublimation temperature, and is often quantified using thermal/optical methods (Huntzicker et al., 1982; Turpin et al., 1990; Chow et al., 2001). When BC is measured based on light absorption spectroscopy techniques, such as an Aethalometer or a Particle Soot Absorption Photometer (PSAP), it is usually referred to as "light absorbing carbon" (Bond and Bergstrom, 2006; Bond et al., 1999). In some cases, the term BC is also commonly interchanged with other terms such as "soot" or "carbon black", while the true definition of BC is still subject to debate (Bond and Bergstrom, 2006). Regardless of the definition, combustiongenerated BC particles are not emitted as pure BC. Diesel particulate matter collected in a conventional diesel exhaust dilution tunnel may contain up to $10-30 \%$ unburned hydrocarbons by mass (Amann and Siegla, 1982). Other research work on vehicular emission shows that the emitted particles often contain a mixture of substances, such as volatile organic compounds, unburned fuel, unburned oil, sulphate, and metal ash, in addition to the black carbon (Burtscher, 2005; Kittelson, 1998; Park et al., 2003). In this work, BC particle is defined as the solid fraction of the combustion generated particle that absorbs a significant amount of radiation in the visible to near-infrared portion of the spectrum.

Atmospheric BC particles are an important global warming agent with radiative forcing similar in magnitude to carbon dioxide (Bond and Sun, 2005). BC alters the radiation budget of the Earth by absorbing incoming radiation from space or radiation emitted from the Earth's surface and then re-emitting it locally as heat energy, thus warming the atmosphere. To accurately estimate and forecast the global warming effect due to $\mathrm{BC}$, knowledge on the light absorption properties of $\mathrm{BC}$ and the effect of condensable materials that typically coat $\mathrm{BC}$ on particle light absorption and thermal emission is required.

Considering light absorption by atmospheric BC particles, the effect due to the presence of non-absorbing materials is complicated. A general increase in particle light absorption is observed with increased quantities of coating material on the BC particles, but the amount of absorption enhancement depends on factors such as refractive index of the coating materials, the size and location of the $\mathrm{BC}$ core, and also the wavelength of the light (Lack and Cappa, 2010; Bond and Bergstrom, 2006; Bond et al., 2006; Slowik et al., 2007a; Fuller et al., 1995; Shiraiwa et al., 2010; Dillner et al., 2001). At the same time particle light absorption decreases when the $\mathrm{BC}$ particle structure collapses from an aggregate or elongated form to a more sphere-like particle (Fuller et al., 1999; Iskander et al., 1991; Liousse et al., 1993). This can occur due to natural atmospheric processing, such as cloud processing and/or condensation of organic and inorganic materials onto BC particles (Ramachandran and Reist, 1995; Huang et al., 1994; Hallett et al., 1989; Pagels et al., 2009; Johnson et al., 2005; Slowik et al., 2007b). Collapse of the BC structure was believed to be one explanation for the decreased particle light absorption observed at some ambient measurement lo- cations (Lewis et al., 2009; Liousse et al., 1993; Liu et al., 2008; Chan et al., 2010). Although the BC morphology and coating issues may appear as independent phenomena, they are closely linked with respect to atmospheric BC particles.

A few studies were conducted in the past using laboratory generated $\mathrm{BC}$ particles coated with various material in an attempt to understand the BC coating issue. Xue et al. (2009) coated $\mathrm{BC}$ particles generated from propane combustion with glutaric acid and succinic acid and then exposed the coated particles to a range of relative humidities. Using a differential mobility analyzer-aerosol particle mass analyzer (DMAAPM) system to measure the morphology of the BC particles, Xue et al. observed that the enhancement in the optical properties of $\mathrm{BC}$ due to coating material depended strongly on the ability of the coating to alter the morphology of the BC particles. Gangl et al. (2008) generated BC particles by spark discharge and coated the particles with non-absorbing carnauba wax. An increase in absorption of up to a factor of 1.8 was observed. Schnaiter et al. (2005) introduced diesel engine combustion generated soot particles into a chamber where secondary organic matter, produced from ozonolysis of $\alpha$-pinene, was added onto the soot particles. An absorption enhancement between 1.8 and 2.1 was observed for an internally mixed situation. Results also suggested that the coated sphere model failed to predict absorption for situations when the coating was insufficient to enclose the freshly emitted aggregate soot particles completely. This discrepancy quickly diminishes as soot particles start to collapse due to the continued deposition of coating material. Coating graphite particles with oleic acid and glycerol, Shiraiwa et al. (2010) observed an enhancement in light absorption of 1.3 to 2 depending on the amount of coating present.

Although laboratory studies are useful, the challenge is to translate the results to the behaviour of $\mathrm{BC}$ particles when they are present and processed in the atmosphere. For this reason, some past studies have attempted to tackle the BC coating and morphology issue using ambient aerosols. The advantage of these kinds of studies is that the coating effect can be studied directly using aerosols present in the atmosphere and thus findings are expected to be more relevant to atmospheric applications. However, the measurements obtained in this work can be difficult to interpret due to the complexity of the ambient aerosols and rapidly changing atmospheric conditions. Knox et al. (2009) used a thermodenuder to remove the particle coating on ambient particles that had different histories based on back trajectory analysis and then estimated their BC mass absorption cross-section (MAC). The MAC results for particles with and without the coating removed were not statistically different due to the large variations of the ambient measurements. Also, the authors suggested that the ambient particles present during the study were too large or heavily coated such that the amount of coating removed in the thermodenuder was insufficient for producing a measurable decrease in the absorption enhancement. Chan et al. (2010) observed that the specific absorption 
cross-section (SAC, which is defined the same as MAC mentioned above) of ambient $\mathrm{BC}$ particles at a rural site was independent or decreasing with increasing particle coating mass or relative oxygenated organic mass. They suggested that the structural collapse of BC particles over time was one of the factors that led to a decrease in particle light absorption. The inconsistencies between observations in the laboratory and field suggest that the atmospheric processing of $\mathrm{BC}$ particles and its relation to light absorption is not well known. A complicating factor in comparing lab and field results is that in the former the characteristics of the particles are known and relatively simple with one type of particle studied at a time. In contrast, in the latter, multiple particle types are typically present at any given time in an external mixture and each may have dramatically different light absorption characteristics.

With the objective to improve the understanding of the effect of non-refractory material and morphology on the light absorption by fine BC particles, this study was conducted with ambient particles, using fast time response instruments, a thermodenuder, and strategically selected measurement locations. The high sensitivity and time resolution used in this study was expected to have an advantage over past studies of atmospheric particle light absorption that relied upon longer integration time measurements (e.g. where $\mathrm{BC}$ was determined using thermal-optical analysis from filters) because of the improved capability to explore the variability in $\mathrm{BC}$ particle light absorption and its relationship with sources and atmospheric processes. The research reported in this paper was conducted before, during and after an intensive field study, referred to as "The Border Air Quality and Meteorology Study" (BAQS-Met; Levy et al., 2010), which occurred in southern Ontario, Canada, in the spring and summer of 2007. There were two major components in this work. The first component was a thermodenuder experiment conducted at one location in the north part of the city of Toronto after the main BAQS-Met period. This was undertaken to characterize how two instruments, namely a Droplet Measurement Technologies (DMT) photoacoustic spectrometer (PA) and a high sensitivity laser-induced incandescence (LII) instrument developed by the National Research Council Canada (NRC), respond to ambient BC particles in the presence of different amounts of total non-refractory particle mass, as measured by an Aerodyne quadrupole Aerosol Mass Spectrometer (AMS). This non-refractory mass may be present as coatings on the $\mathrm{BC}$ particles or as separate externally-mixed particles with different amounts of $\mathrm{BC}$ at their core.

In Toronto, concurrent measurements with the three instruments were obtained over several days with an alternating flow path - continuous repetitions of five minutes through the thermodenuder and five minutes bypassing the thermodenuder. It was hypothesized that this unique combination of instrumentation would offer a valuable opportunity for studying $\mathrm{BC}$ particles. This is because of the different $\mathrm{BC}$ measurement principles for LII and PA. The former was expected to be less affected by coatings, thus only responding to $\mathrm{BC}$ by detecting the thermal emission produced by super-heated refractory fine carbon particles (e.g. Snelling et al., 2000, 2005; Liu et al., 2006; Schwarz et al., 2006, 2008; Moteki and Kondo, 2007). The light absorption ( $\left.B_{\text {abs }}\right)$ measurements by PA were, however, observed to be sensitive to coatings (e.g. Knox et al., 2009). This is likely due to the lensing effect of the coatings and the lower laser power involved in producing the signal detected in the PA, which is derived from pressure waves produced by thermal heating of the boundary layer surrounding the particles. A possible secondary source of the pressure waves in the PA could arise from evaporation of coating materials on the particles. Murphy (2009) found that water evaporation from ambient particles could reduce the photoacoustic signal however this result is strongly dependent on the mass accommodation coefficient of water on the particle which depends on the particle composition. In an internally mixed situation with significant amount of organics present on the particle, such as a situation with aged particles, this interference diminishes because the kinetics of the evaporation is slowed down. Other studies that focused on the impact of water evaporation on the photoacoustic signal also found that in most atmospheric applications the impact is small (Raspet et al., 1999, 2003). In this study, the evaporation impact from non-refractory materials was not investigated and is assumed not to affect the light absorption measured from the PA. In any case if the lensing effect impacts the total absorption in LII measurements, the technique of Snelling et al. (2005) automatically compensates for this by measuring the transient $\mathrm{BC}$ particle temperature during the LII process, resulting in an unaffected measurement of $\mathrm{BC}$ volume and mass.

In the second component of our experiment, the instruments were deployed to contrasting locations to measure the ambient BC particles using the LII and PA, but without thermodenuder alterations. These measurements were undertaken to determine if it is possible to observe in-situ urban to regional scale variations in the coating effect on $\mathrm{BC}$ light absorption properties within different air masses. It was expected that these data would provide new insights into how the particle light absorption varies across a realistic range of atmospheric conditions where there would be differences in the amount of particle coating mass, differences in the extent of external mixing, and differences in particle morphology. Through the use of a mobile laboratory, measurements were collected just before the main BAQS-Met study period in an urban street canyon with heavy diesel bus traffic and at a location adjacent to a highway, both of which were in Ottawa, Ontario. During BAQS-Met the mobile lab was deployed to an industrially-impacted urban site in west Windsor, Ontario, and to rural locations in southwestern Ontario.

Through these strategic deployments our objective was to quantify the range of variability in the coating enhancement in $\mathrm{BC}$ light absorption, to understand how quickly the enhancement can change due to changes in coating relative to $\mathrm{BC}$ mass, and possible causes of these changes related to $\mathrm{BC}$ 
particle source and atmospheric processing. In this study, enhancement was quantified through determination of the specific absorption cross-section (SAC), which is defined as the ratio of $\mathrm{BC}$ light absorption $\left(B_{\mathrm{abs}}\right)$ to $\mathrm{BC}$ mass concentration. This term has the same meaning as mass absorption crosssection (MAC) as defined in Bond and Bergstrom (2006). The terms specific attenuation cross-section or specific attenuation coefficient have been used previously (e.g. Liousse et al., 1993; Sharma et al., 2002; Snyder and Schauer, 2007; Chan et al., 2010), but is somewhat ambiguous in this context as it implies that scattering is ignored in determining attenuation. The SAC results in this study were quantified with 1 min time resolution from a combination of measurements using the LII and PA instruments.

\section{Sampling and instrumentation}

\subsection{Thermodenuder experiment}

From 15-21 August 2007, ambient measurements were taken simultaneously by the three instruments at a suburban/commercial location about $17 \mathrm{~km}$ north of downtown Toronto, Ontario. The main source of anthropogenic emissions in this area is from vehicles along a busy four lane road $150 \mathrm{~m}$ west of the measurement site. During morning and evening, rush hour traffic along this road is often "stop and go", but is dominated by gasoline vehicles, while during the day heavy and light duty diesel trucks and buses also use this road frequently.

The instruments were housed inside a mobile laboratory, also known as the Canadian Regional and Urban Investigation System for Environment Research (CRUISER), which was connected to an external source of power. Ambient air was drawn into CRUISER at a $16.71 \mathrm{~min}^{-1}$ flow rate through a cyclone to achieve a $2.5 \mu \mathrm{m}$ size cut and to the entrance of an automated sampling system through a $3.18 \mathrm{~cm}$ OD stainless steel sampling tube of $1.88 \mathrm{~m}$ in length. Inside CRUISER this tube is surrounded by a $15.24 \mathrm{~cm}$ PVC pipe containing an external sheath air flow drawn from outside, which serves to keep the sample air containing particles at ambient temperature as long as possible to avoid condensation in summer and evaporation in winter. The location of the cyclone, which is extended out of the roof of CRUISER, is about $3.6 \mathrm{~m}$ above ground.

At the automatic sampling system (Fig. S1 in the Supplement), $111 \mathrm{~min}^{-1}$ flow is drawn from the base of the sampling inlet to supply the necessary flow for all instruments used for the thermodenuder experiment. Every five minutes the solenoid value changed position allowing the ambient sample to either pass through or bypass the thermodenuder (Dekati model ELA-111). The total residence time in the thermodenuder was experimentally estimated to be about $8 \mathrm{~s}$ based on the operation conditions. The Dekati thermodenuder consists of the heater and the absorber sections. When the ambient particles passed through the heater section which was operated at $\sim 300^{\circ} \mathrm{C}$, most of the non-refractory components in the sample were evaporated. In the absorber section, the vapor components, particularly the hydrocarbons, were absorbed and removed from the airstream by active charcoal while at the same time being cooled by ambient air operated at a flow rate of $1001 \mathrm{~min}^{-1}$. The temperature of the sample exiting the thermodenuder was typically the same as the temperature of the ambient air. Information regarding the particle losses in the thermodenuder is provided in Sect. 3.1.1.

Air sampled through the thermodenuder (denoted as denuded sample) or bypassing the thermodenuder (denoted as non-denuded sample) was then drawn into the PA (1.0 $1 \mathrm{~min}^{-1} ; 2 \mathrm{~m}$ of $0.64 \mathrm{~cm}$ O.D. mixed stainless steel and silicon conductive tubing) and LII $\left(8.01 \mathrm{~min}^{-1} ; 4 \mathrm{~m}\right.$ of $0.64 \mathrm{~cm}$ O.D. silicon conductive tubing) for measuring light absorption and inferred $\mathrm{BC}$ mass concentration, and the AMS $\left(83 \mathrm{~cm}^{3} \mathrm{~min}^{-1} ; 0.5 \mathrm{~m}\right.$ of $0.64 \mathrm{~cm}$ O.D. silicon conductive tubing) for measuring the mass concentrations of the nonrefractory components in the ambient particles including organic matter, sulphate, ammonium, and nitrate.

\subsection{Ottawa highway and urban street canyon}

The Ottawa measurements consist of a small data set that was acquired with CRUISER running on generator power at two different locations in Ottawa: (1) an area located near a local highway (near the intersection between HWY 417 and HWY 174) with sampling during the afternoon rush hour period and (2) a location in the Ottawa downtown area that is surrounded by tall buildings (Albert Street and Elgin Street) with sampling during the morning rush hour period when there is constant diesel bus traffic bringing commuters into the downtown core. The two locations were chosen to study how the PA and LII BC signals and their ratios change with different amounts of particle coating mass with the emitted particles having a limited and some degree of atmospheric processing, at the street canyon and highway locations, respectively. No thermodenuder was used during the study as the goal was to observe changes in the light absorption properties induced by urban- to regional-scale atmospheric processes.

\subsection{BAQS-Met field study}

The BAQS-Met field study was part of the second field component of this study, during which CRUISER was deployed to various locations inside and outside the city of Windsor. The study area is commonly impacted by emissions from the Detroit-Windsor area and other regional sources transported to the sampling locations. When it was inside the city, CRUISER was parked the West Windsor Water Pollution Control Plant for several days for continuous measurements at which time it was connected to an external source of power. This location is within a couple kilometers of a 
large steel mill and a coal fired power plant, as well as a range of other industries in both Windsor and Detroit. The impact of these on the measurements is discussed in detail below. From time to time, CRUISER, running on generator power, was driven to different locations outside, but within approximately $100 \mathrm{~km}$ of the Detroit-Windsor area. CRUISER stopped for periods ranging from about $15 \mathrm{~min}$ to one hour at locations expected to be experiencing different air masses affected by local lake-induced circulation patterns, which could potentially alter the extent of air mass processing within relatively short distances. During the BAQSMet field study, the PA and LII were used to provide particle light absorption coefficient and inferred BC mass measurements while the AMS was used to measure the nonrefractory component in the particles at the same time. The thermodenuder was not used during the BAQS-Met study as the goal was to observe changes in the light absorption properties induced by local to regional scale atmospheric processes.

\subsection{Black carbon measurement}

In this study, a Droplet Measurement Technology photoacoustic spectrometer (PA) and a high sensitivity laserinduced incandescence (LII), developed by the National Research Council Canada (NRC), were used for measuring BC in the ambient particles. The PA and LII are both in-situ instruments capable of measuring BC particle content directly from the airstream. PA does not measure BC mass directly but measures the particle light absorption coefficient $\left(B_{\mathrm{abs}}\right)$, which is influenced by the BC mass in the particles. LII measures the thermal emission from the laser-heated particles, which is directly proportional to the BC mass. Therefore, $\mathrm{PA}$ and LII are close to being first principle instruments for measuring BC mass concentration (Moosmüller et al., 2008).

\subsubsection{Photoacoustic spectrometer (PA)}

In the PA, the laser beam ( 2 watt, $781 \mathrm{~nm}$ ) is modulated at a rate of $1500 \mathrm{~Hz}$ as it passes through the particle stream inside the PA resonator. This causes the surrounding air to expand and contract at the modulated frequency. The pressure disturbance (i.e. acoustic signal) is amplified within the photoacoustic resonator and then measured by a microphone. The acoustic signal is proportional to the black carbon mass concentration and reported as an absorption coefficient, $B_{\text {abs }}$ (Arnott et al., 1999; Faxvog and Roessler, 1982; Lack et al., 2006). The sensitivity of the PA and the signal to noise ratio vary from site to site but generally the detection limit of the $B_{\text {abs }}$ measurements is about $0.05(\mathrm{M} \mathrm{m})^{-1}$. Dividing the absorption coefficient by the specific absorption cross-section (SAC) gives an estimate of the BC mass concentration. During all measurements, the PA was operated at a $1 \mathrm{~s}$ time resolution, but the data were smoothed to $1 \mathrm{~min}$ averages before comparison with the LII.
The PA is equipped with a reciprocal nephelometer for measuring particle light scattering. The detector in the instrument (photo multiplier tube) has a cosine response and is mounted on the middle sideway of the resonator to capture scattered light between $5^{\circ}$ and $175^{\circ}$. The signal is processed and reported as the particle light scattering coefficient. The truncation of the detection angle in the nephelometer can lead to significant under-estimation of the scattering signal for aged particles as the forward and backward scattering can not be effectively measured. As particle size distribution measurements were not available in this study it is impossible to accurately predict this uncertainty. As a result, no scattering measurements will be presented in this work.

All properties are measured for an ensemble of particles detected within the sample volume of the instrument; this is not a single particle detection instrument.

\subsubsection{Laser-induced incandescence instrument (LII)}

In the case for the LII, BC is heated by a high energy short pulse laser $(200 \mathrm{~mJ} /$ pulse, $7 \mathrm{~ns}$ FWHM duration, $1064 \mathrm{~nm}$ wavelength). The laser energy is absorbed by the BC component in the particles causing a rapid increase in temperature. During the heating process, temperature of the $\mathrm{BC}$ component in the particle approaches $\sim 4000 \mathrm{~K}$, just below the sublimation temperature for BC. At these temperatures the particles incandesce (as a form of near-blackbody emission) with sufficient intensity to be detected. At the end of the laser pulse, heating ends and the $\mathrm{BC}$ particles cool rapidly, over a period of approximately one microsecond, until the incandescence signal is no longer detectable. The energy loss to the surrounding air is proportional to the active surface area of the BC particles. The NRC system is a high sensitivity variant of the auto-compensating LII technique, also embodied in the LII 300 instrument produced by Artium Technologies, which employs two color pyrometry (at wavelengths of $445 \mathrm{~nm}$ and $750 \mathrm{~nm}$, detected by photomultipliers) to determine the particle temperature from the incandescence signal (Smallwood, 2008). Based on the absolute magnitude of the incandescence signals combined with the BC particle temperature and the rate of heat losses to the surrounding air, the $\mathrm{BC}$ concentration as well as the spherule diameter (primary particle size - PPS) can be determined, respectively (Mewes and Seitzman, 1997; Snelling et al., 1998, 2000, 2005; Wainner and Seitzman, 1999; Bryce et al., 2000; Liu et al., 2006; Schulz et al., 2006). The BC concentration is reported as a volume fraction (BC volume to air volume in the sample, or soot volume fraction - SVF) and can be converted to a mass concentration through multiplying by the $\mathrm{BC}$ material density $\left(\rho_{\text {soot }}\right)$ of $1.9 \pm 0.1 \mathrm{~g} \mathrm{~cm}^{-3}$ (Smallwood, 2008). The detection limit of the high sensitivity LII for the SVF is typically $8 \times 10^{-15}$, this is equivalent to a $\mathrm{BC}$ concentration of $15 \mathrm{ng} \mathrm{m}^{-3}$ (Smallwood, 2008). All properties are measured for an ensemble of particles detected within the sample volume of the instrument; this is not a single particle detection 
instrument. Although the LII instrument acquires data at a rate of $20-\mathrm{Hz}$, the results were reported at 1 -min time resolution during all measurements used in this study for ease of comparison with the other instruments.

\subsubsection{Primary particle size (PPS)}

Particle morphology is known to play a role in affecting particle light absorption (Fuller et al., 1999; Martins et al., 1998) and the potential for such an effect was considered in this study through the use of the primary particle size (PPS) measured by the LII. Theoretically, the PPS refers to the diameter of the individual spherule that makes up BC particle chains or aggregates. In the low fluence approach of the high sensitivity LII used in this study, the dominant cooling mechanism for the $\mathrm{BC}$ particle is conduction to the surrounding gas. During the conduction phase, the temperature difference between the $\mathrm{BC}$ particles and the ambient gas decays monotonically in a near-exponential manner (Snelling et al., 2000). By measuring the temperature of the $\mathrm{BC}$ particle in real time (on a nanosecond time scale) with the two-color pyrometry approach, the rate of temperature decay can be determined. From this the specific surface area and an effective primary particle diameter can be determined, assuming the spherules within an aggregate are in point contact with each other. This approach is more fully described in Schulz et al. (2006) and Mewes and Seitzman (1997) and details on the influence of primary particle diameter distributions can be found in Liu et al. (2006).

Observations show that freshly emitted BC particles measured from diesel exhaust usually have PPS values ranging from $40 \mathrm{~nm}$ to about $80 \mathrm{~nm}$ (Smallwood et al., 2002; Snelling, 2000; Smallwood, 2008) while gasoline BC particles have even smaller PPS values from 10 to $40 \mathrm{~nm}$. This is demonstrated in Fig. S2 in the Supplement, which summarizes PPS measurements for four gasoline vehicles and one diesel truck. These measurements were acquired from a chassis dynamometer test cell at the Emission Research and Measurement Section facility of Environment Canada in Ottawa. All measurements were taken directly from a constant volume sampling (CVS) dilution system, and therefore the $\mathrm{BC}$ particles have little chance for undergoing any atmospheric processing as they normally would when released into the atmosphere. These results support the fact that there are more variations in the BC PPS when emitted during transient cycles and at that PPS values for freshly emitted gasoline BC particles are significantly smaller than that from diesel exhaust.

Over time in the atmosphere, emitted particles undergo atmospheric processes and pick up condensable material such as organics and sulphate (e.g. Johnson et al., 2005), and during cloud processing water molecules continue to condense on and evaporate from the $\mathrm{BC}$ particles (e.g. Ramachandran and Reist, 1995; Huang et al., 1994; Hallett et al., 1989). During such processes the different amounts and types of material present on the $\mathrm{BC}$ aggregate may induce a change in surface tension of the $\mathrm{BC}$ particle causing the structure to collapse. As the $\mathrm{BC}$ aggregate collapses, some of the surface area becomes shielded and is not available for heat transfer and this leads to an increased PPS value as inferred from LII (Smallwood, 2008). It is also significant to note that the PPS value estimated from the LII represents the ensemble average PPS value for all the individual BC particles within a single measurement sample, i.e.

PPS $_{\text {obs }}=\frac{\sum_{i=1}^{N} \operatorname{PPS}_{i}}{N}$

In other words, a change in the observed PPS value is expected whenever there is an introduction of $\mathrm{BC}$ particles with a PPS value different from those already present in the atmosphere. For example during a situation when there is a continued release of freshly produced $\mathrm{BC}$ particles into the atmosphere, it is expected that the observed PPS value would decrease relative to aged and processed atmospheric BC particles. Having said that, the degree of which the observed PPS value changes depends on both the PPS values of the freshly emitted and transported BC particles as well as the PPS values of the $\mathrm{BC}$ particles pre-existing in the atmosphere.

Given that the PPS determined from LII is also affected by the structure of the aggregates and the degree of shielding (Liu et al., 2006), in this study an increasing trend of the PPS value observed is assumed to be a surrogate for particle collapse. However, due to the complexity of the aggregate structure and the source of the BC particles, the degree of collapse may not be a continuous variable but a categorical variable with complex behaviour. Nonetheless, this assumption is expected to be reasonable for combustion generated BC particles (e.g. diesel aggregates), particularly during the earlier part of their period in the atmosphere when they start as more branched structures, allowing LII to detect the smaller PPS associated with the source of emission. Conversely, in situations when the original aggregate is less branched or partially collapsed, it is likely that PPS will be less variable over time and the lower and upper limit of the PPS will appear to be more constrained. Note that the PPS value inferred from LII does not directly measure the structure of the $\mathrm{BC}$ particles. It is possible for particles to have different structures but still be made up by spherules with the same diameter, which may or may not impact the PPS inferred by LII. When there is a change in the ratio of a mixture of gasoline $\mathrm{BC}$ particles with diesel BC particles, the analysis of the PPS from atmospheric particles becomes further complicated. The uncertainty imparted by this variability may make it more difficult to infer physical patterns when comparing PPS among widely separated time periods or measurement locations. 


\subsection{Aerosol mass spectrometer}

During this study, the non-refractory components in the aerosol were measured by an Aerodyne quadruple Aerosol Mass Spectrometer (AMS). Inside the AMS, particles are drawn from ambient condition through an aerodynamic lens to focus into a narrow beam, accelerated to specific aerodynamic velocities that are related to the vacuum aerodynamic diameters of the particles. The particles impact on a resistively heated surface where all volatile and semi-volatile components are vaporized. Ionized by electron impact, fragments are then detected by a quadrupole mass spectrometer at about $10^{-7}$ torr (Jayne et al., 2000; Jimenez et al., 2003; Allan et al., 2003). During this study, the AMS was operated in the mass and time of flight modes providing average mass concentrations of the organic matter, sulphate, ammonium, and nitrate on the particles in the size range from approximately 40 to $1000 \mathrm{~nm}$. The total non-refractory mass ("non-refractory mass") was assumed to be given by the sum of these four fractions. The typical detection limit of the AMS measurements for this study is about $0.5 \mu \mathrm{g} \mathrm{m}^{-3}$. The time resolution used for the AMS during the thermodenuder experiment was $5 \mathrm{~min}$. For the Ottawa field measurements the time resolution was $5 \mathrm{~min}$. For the BAQS-Met measurements, the time resolution was 2 and 5 min when measurements were taken at various locations away from the city and 5 or 15 min when CRUISER was parked in the city. For all the AMS measurements, the collection efficiency (CE) was assumed to be unity.

\section{Results and discussion}

\subsection{Thermodenuder experiment}

\subsubsection{Particle losses in the thermodenuder}

In practice, particle losses in the thermodenuder are not a critical issue in this study because the $B_{\text {abs }}$ and SVF measurements are equally affected and it is their comparison that was of interest. Nonetheless, in order to estimate the degree of particle loss in the thermodenuder, a separate experiment was carried out. Ambient air was continuously passed through either the unheated thermodenuder or a matched bypass path in 5-min intervals while a TSI Fast Mobility Particle Sizer (FMPS) measured the particle number size distributions. During the same time, ambient $\mathrm{NO}$ and $\mathrm{O}_{3}$ were monitored continuously to assess the amount of variability in the local ambient air mass. During a 20-min period with relatively stable $\mathrm{NO}$ and $\mathrm{O}_{3}$ levels the particle number size distributions measured through the unheated thermodenuder and the bypass path were averaged separately and these are presented in Fig. S3 of the Supplement. Also shown in the figure are the percentage particle losses for different size bins. For most sizes, the particle loss is less than $20 \%$ with much of this is related to parts of the distribution where the number
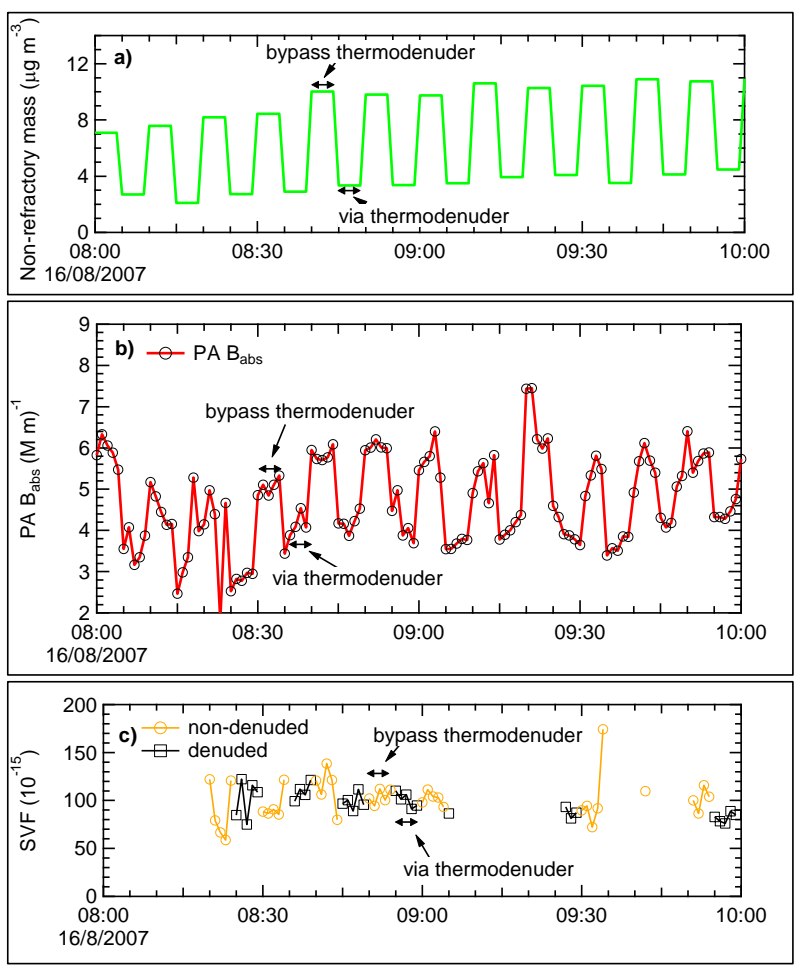

Fig. 1. Variations of (a) the non-refractory mass measured by the AMS during the thermodenuder experiment for a 2-h period on 16 August 2007, (b) the particle light absorption ( $B_{\text {abs }}$ ) measured by the photoacoustic spectrometer during the same period, and (c) the soot volume fraction (SVF) measured by the laser-induced incandescence instrument during the same period. For clarity, the SVF measured during the denuded and non-denuded periods are presented by different markers.

concentration is low (i.e. $7 \mathrm{~nm}$ and $70 \mathrm{~nm}$ ). As will be discussed in Sect. 3.1.2, due to variability in ambient concentrations, there were differences in $\mathrm{BC}$ mass concentration between consecutive measurements through the bypass and the thermodenuder. These tended to be smaller than 10-15\% and in both directions indicating that particle losses in the denuder were not the main cause of the variability, which is likely because the size of particles experiencing the most loss contributed less to the observed BC mass.

\subsubsection{Black carbon observations from the PA and LII}

The main purpose of the thermodenuder experiment was to test the hypothesis that the presence of non-refractory mass influences the signal from the PA, but not the LII. The thermodenuder was used to remove a significant portion of the semivolatile material from the particles to compare how these two instruments responded with and without this material. Figure 1a shows a time series subset of the non-refractory mass, defined as the sum of organic matter, sulphate, ammonium, and nitrate mass concentration measured from the 

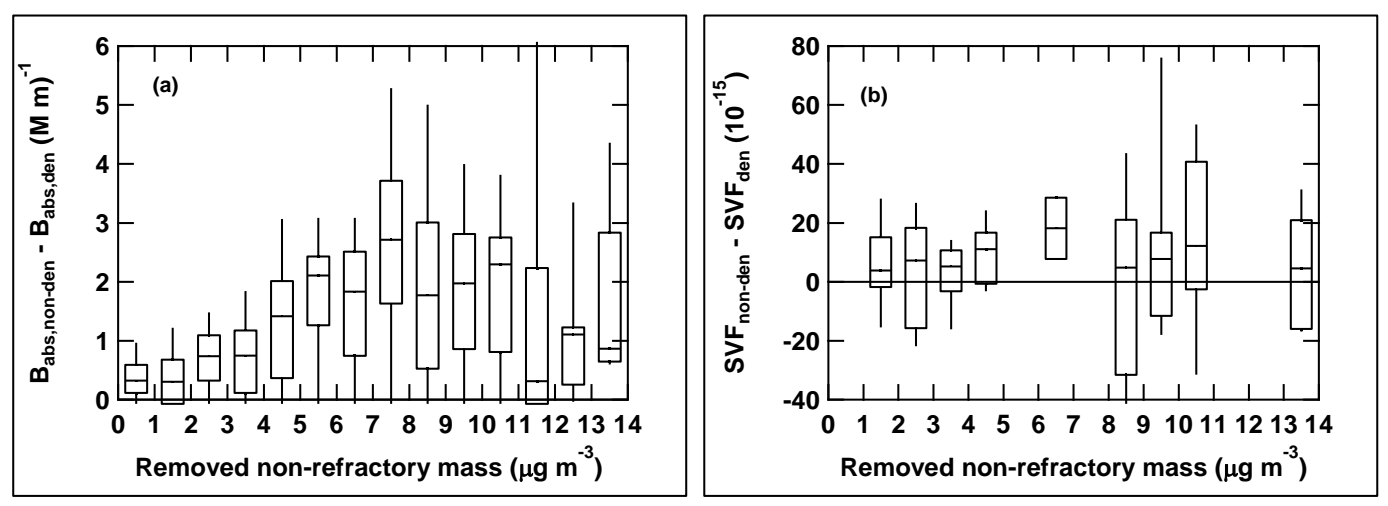

Fig. 2. The difference in (a) particle light absorption coefficient and (b) soot volume fraction between the non-denuded and denuded condition as a function of non-refractory mass removed by the thermodenuder. Each individual box represents the 25th, 50th, and 75 th percentiles of the measurement values while the 10th and 90th percentiles are represented by the bottom and top whiskers, respectively.

AMS during the thermodenuder experiment. Every other five minute period, samples passed through the thermodenuder causing a substantial decrease in non-refractory mass in the range of 4-8 $\mu \mathrm{g} \mathrm{m}^{-3}$ (loss of 60-70\%).

Figure $1 \mathrm{~b}$ shows the $B_{\mathrm{abs}}$ measured by the PA during the same time period as in Fig. 1a. This example demonstrates that there is a change in the PA instrument response, interpreted as a change in the $B_{\mathrm{abs}}$, when the thermodenuder removed non-refractory mass. This example suggests that at least a portion of this non-refractory mass was present on the particles containing the majority of the $\mathrm{BC}$ being detected by the PA. In contrast, the SVF measured by the LII during the same period of time (Fig. 1c) shows no distinct changes between the denuded (black squares) and non-denuded (orange circles) conditions. Between adjacent non-denuded and denuded periods, the difference in SVF varies from 10-15\%. As discussed above, these differences were predominantly to ambient $\mathrm{BC}$ variations although there are some particle losses in the thermodenuder (Sect. 3.1.1). However, the comparison of how the PA and LII responded is not affected by either of these factors due to their concurrent measurement.

Figure 2a summarizes the difference in particle light absorption (i.e. changes in PA signal) between the non-denuded and denuded conditions during the entire thermodenuder experiment. The result is presented as a function of nonrefractory mass that was removed by the thermodenuder (i.e. difference between the non-denuded and denuded cases, as determined by the AMS). These results demonstrate that there is an observable and significant change in value of the particle $B_{\text {abs }}$ measured by the PA as the amount of nonrefractory mass is changed. Figure $2 b$ shows the difference in SVF signal measured by the LII as a function of removed non-refractory mass. In comparison to the PA observations, regardless of the amount of the non-refractory mass, there is no significant change in the SVF signal measured by the LII.

The increase in the change in $B_{\text {abs }}$ with increasing nonrefractory mass in Fig. 2a is interesting. It could be related to coating thickness on the $\mathrm{BC}$ particles, but features such as the large drop in the change in $B_{\text {abs }}$ at the higher nonrefractory concentrations need to be explained. The design of the thermodenuder experiment cannot resolve whether all the non-refractory mass measured is actually coating the $\mathrm{BC}$ particles, which are predominantly associated with emission in Toronto and close to the measurement site (i.e. BC disperses relatively quickly so more local and current emissions from combustion can be expected to dominate the PA and LII signals), or is associated with separate externally mixed particles that may contain relatively less BC. An increase in the relative amount of high non-refractory mass particles that remain externally mixed with the local BC particles could lead to the behaviour shown in Fig. 2a. BC particle morphological changes could also play a role. Indeed, specific differentiation of internally and externally mixed conditions, with the latter likely always the case to some degree, cannot be determined with the AMS, LII and PA measurements alone. Knowledge of the airmasses impacting the measurement site and aerosol formation processes are needed to make inferences and these factors will be explored in more detail in the next Sect. 3.1.3.

The contrasting results between the non-refractory mass impact on PA and LII determination of BC mass, which were expected, are related to differences in the measurement principles between the PA and LII. In the case of LII, the absorbed laser energy is sufficient to heat the BC to temperatures that will evaporate any volatile or non-refractory substances on the particle, eliminating their role in the transfer of the laser energy to the $\mathrm{BC}$ in the particle and hence in the absolute measurement of BC. Secondly, the auto-compensating LII approach (Snelling, 2005) adjusts, by directly measuring the particle temperature on a nanosecond timescale, for any increase in particle temperature due to lensing effects and any reduction in particle temperature due to the evaporation of volatiles. Thus, as hypothesized, the amount of nonrefractory mass does not influence the LII measurements of 
SVF. This result is consistent with observations from other studies using laser-induced incandescence based instruments such as the Single Particle Soot Photometer (e.g. Slowik et al., 2007a).

In the case of the PA, much less, if any evaporation occurs due to the lower energy of the laser, which has limited impact on particle temperature. Consequently, in the case of an internally mixed situation, the presence of the non-refractory mass contributes to a lensing effect by concentrating the PA laser energy into the $\mathrm{BC}$ core thus enhancing absorption, similar to what is predicted to occur when atmospheric particles interact with the sun's energy (Bond et al., 2006).

The thermodenuder experiment results provide evidence that the $\mathrm{BC}$ mass concentration estimated from the LII is the true $\mathrm{BC}$ mass concentration regardless of whether the $\mathrm{BC}$ particles are internally or externally mixed. This is important because combining the in-situ $B_{\text {abs }}$ and SVF signals and with the use of soot material density $\left(\rho_{\text {soot }}\right)$ gives a high time resolution estimation of the BC specific absorption cross-section $\left(\mathrm{SAC}\right.$; i.e. $\left.\mathrm{SAC}=B_{\mathrm{abs}} /\left(\mathrm{SVF} \times \rho_{\text {soot }}\right)\right)$. In addition, as will be discussed in the next section, comparing the real-time SAC values with other non-refractory quantities can provide valuable information for differentiating an internally mixed situation from an externally mixed condition providing more insight into factors affecting the variability in the SAC and the impact of coatings.

\subsubsection{SAC and non-refractory mass relationship and the influence of internally and externally mixed aerosol}

The relationship between $B_{\text {abs }}$ and the non-refractory mass (Fig. 2a) is investigated in this section to reveal how these two variables and other parameters are connected. Given the complexity of this relationship it is necessary to examine time series of measurements during the Toronto thermodenuder experiment. The first panel in Fig. 3 shows the time series of 5 min BC mass concentration based on the SVF for two complete daytime periods. The next panel shows the variation in the non-refractory mass to $\mathrm{BC}$ mass ratio during the same time period. The following panels provide the time series of the SAC and mass concentrations of the organic matter, sulphate, and nitrate, respectively. The final panel (Fig. 3g) shows the time series of the PPS. In each panel, the denuded and non-denuded measurements are plotted separately. The side by side comparisons provided by these panels illustrate how quickly the pattern can change in an urban location, thus demonstrating the importance of the high temporal resolution measurements.

In Fig. 3a, the general pattern of the two days shows that the $\mathrm{BC}$ concentration starts high in the morning due to the presence of a relatively shallow surface inversion layer containing urban morning rush hour emissions plus any overnight emissions that have accumulated. The BC mass concentration then gradually decreases over the course of the morning because of the break up of the inversion and increased boundary layer mixing, as well as reduced local traffic due to termination of rush hour. When the boundary layer rises and vertical mixing increases there is good potential that the recently emitted particles below the inversion, which can be expected to be relatively similar due to the importance of traffic emissions, will mix with different particles residing above the boundary layer. This likely leads to a relatively distinct externally mixed situation, which influences the relationships between the measurements shown in Fig. 3 differently than in the morning.

Comparing 16 and 17 August, it can be seen that these days were different. While the general temporal pattern in $\mathrm{BC}$ was similar, the concentration was slightly lower on the 17th. However, the other concentration measurements from the AMS show that levels of non-refractory mass were considerably higher on the first day (16 August). Organic matter was 2-4 times higher and sulphate, although not high relative to regional events that can affect Toronto with concentrations above $20 \mu \mathrm{g} \mathrm{m}^{-3}$, was about 4 times higher during the afternoon. Ammonium (not shown) behaved similar to sulphate. The difference in the behaviour of nitrate was quite dramatic with a significant morning peak on the 16th, which disappeared by mid morning, and no appreciable nitrate on the 17th. The time series of the non-refractory mass to BC mass ratio (Fig. 3b), which is potentially related to particle coating thickness in an internally mixed situation, shows a slow but gradual increase in value over time on each day. However, it begins to fluctuate by mid morning on the 16th and by early afternoon on the 17th. Consistent with the higher non-refractory mass concentrations on the 16th, this ratio is also higher on this day. Also, the SAC (Fig. 3c) is generally higher on the 16th, which suggests that at least some of the additional non-refractory mass is on the same particles containing the majority of the BC (i.e. coating).

Examination of the concurrent changes in the nonrefractory mass to $\mathrm{BC}$ mass ratio and in the SAC between non-denuded and denuded measurements and over time reveals, we hypothesize, the extent to which the non-refractory mass was coating the BC detected by the LII. Specifically, if the non-refractory mass to $\mathrm{BC}$ mass ratio changes significantly when the particles pass through the denuder and the SAC decreases, then it is more likely that at least some of the non-refractory mass removed by the denuder was coating the particle and enhancing SAC. Consider the first 90$120 \mathrm{~min}$ on the morning of 16 August when nitrate was relatively high. Typically, in the summer when nitrate increases overnight due to lower temperatures and higher relative humidity it will form locally and both nighttime processes that are responsible for nitrate formation most likely lead to ammonium nitrate condensing or forming on pre-existing particles. Prior to about 09:30 on 16 August, Fig. $3 \mathrm{~b}$ and c show a clear separation between the non-denuded and denuded time series and a corresponding drop in nitrate shown in Fig. $3 \mathrm{f}$. Continuing through to about 10:10 the difference in the two 

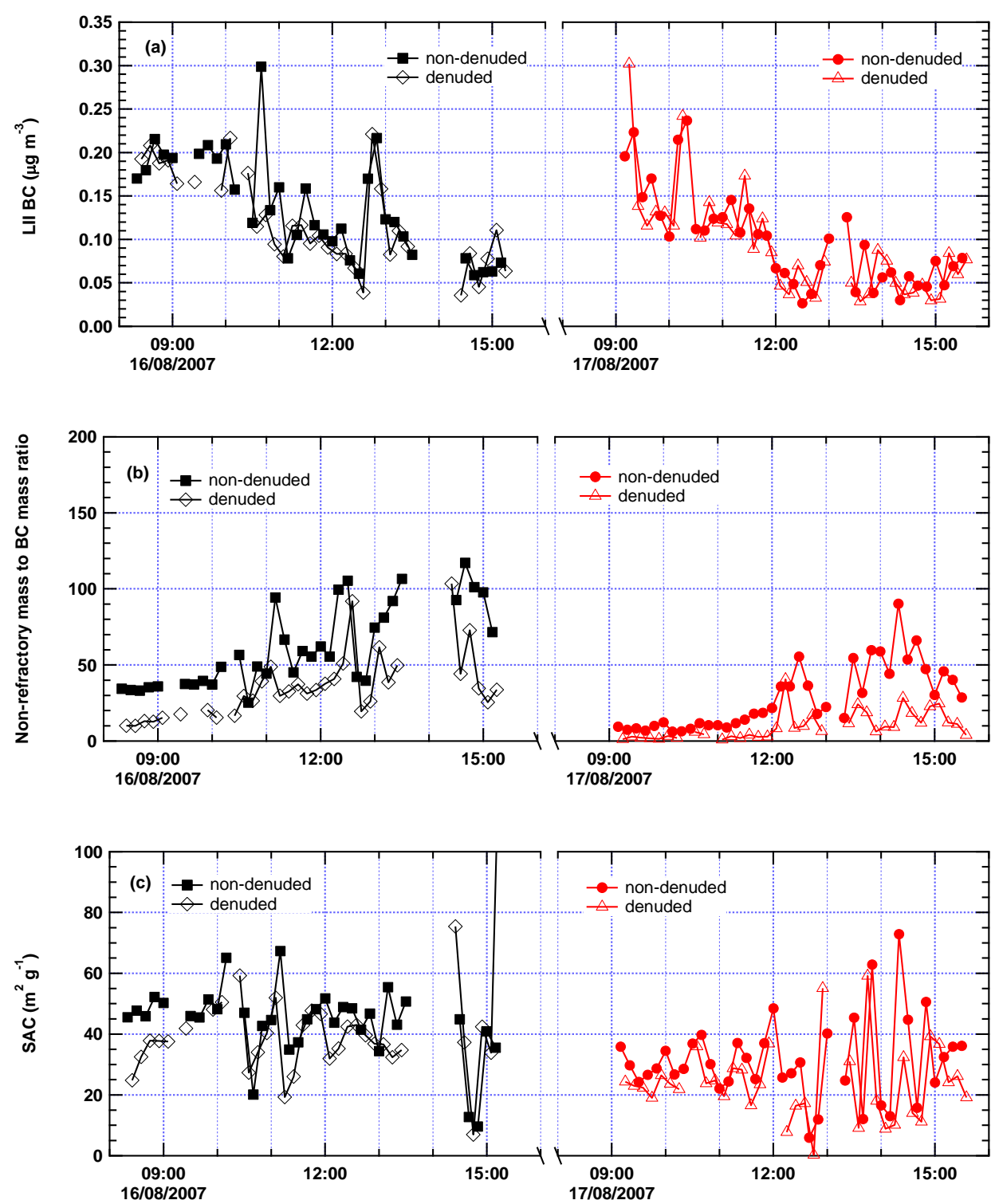

Fig. 3. Time series of (a) black carbon mass concentration, (b) non-refractory mass to BC mass ratio, (c) specific absorption cross-section, (d) organic matter mass concentration, (e) sulphate mass concentration, (f) nitrate mass concentration, and (f) PPS during the two days of the thermodenuder experiment.

SAC values is less clear even though nitrate was relatively high. While for some of the points in this period the nondenuded to denuded SAC is noticeably larger, there are fluctuations in this separation, which may be due to more-rapid changes in the nature of the particles that the sequential integrated $5 \mathrm{~min}$ measurements could not resolve. However, overall, this example demonstrates how the series of measurements in Fig. 3 can be used to gain insight into the particle mixing state and the impact of increased coating mass on the SAC. Other examples, which are a more difficult to disentangle, are described in the next several paragraphs.
There was a slight increase in sulphate mass concentration (Fig. 3e) over time each day, which was more evident in the morning on the 16th and in the afternoon on the 17th. On the first day there was a sharp drop in sulphate at 11:30 followed by an increase to a peak at 13:00 and then a steady decrease. The organic matter also experienced this rise to a peak and then a decrease during the afternoon. These changes in the non-refractory mass can be seen to affect the behaviour of the non-refractory mass to $\mathrm{BC}$ mass ratio and the SAC. Not surprisingly, the ratio follows the same pattern due to the added mass. However, the SAC shows little consistent change. In the morning, as sulphate is rising gradually, 

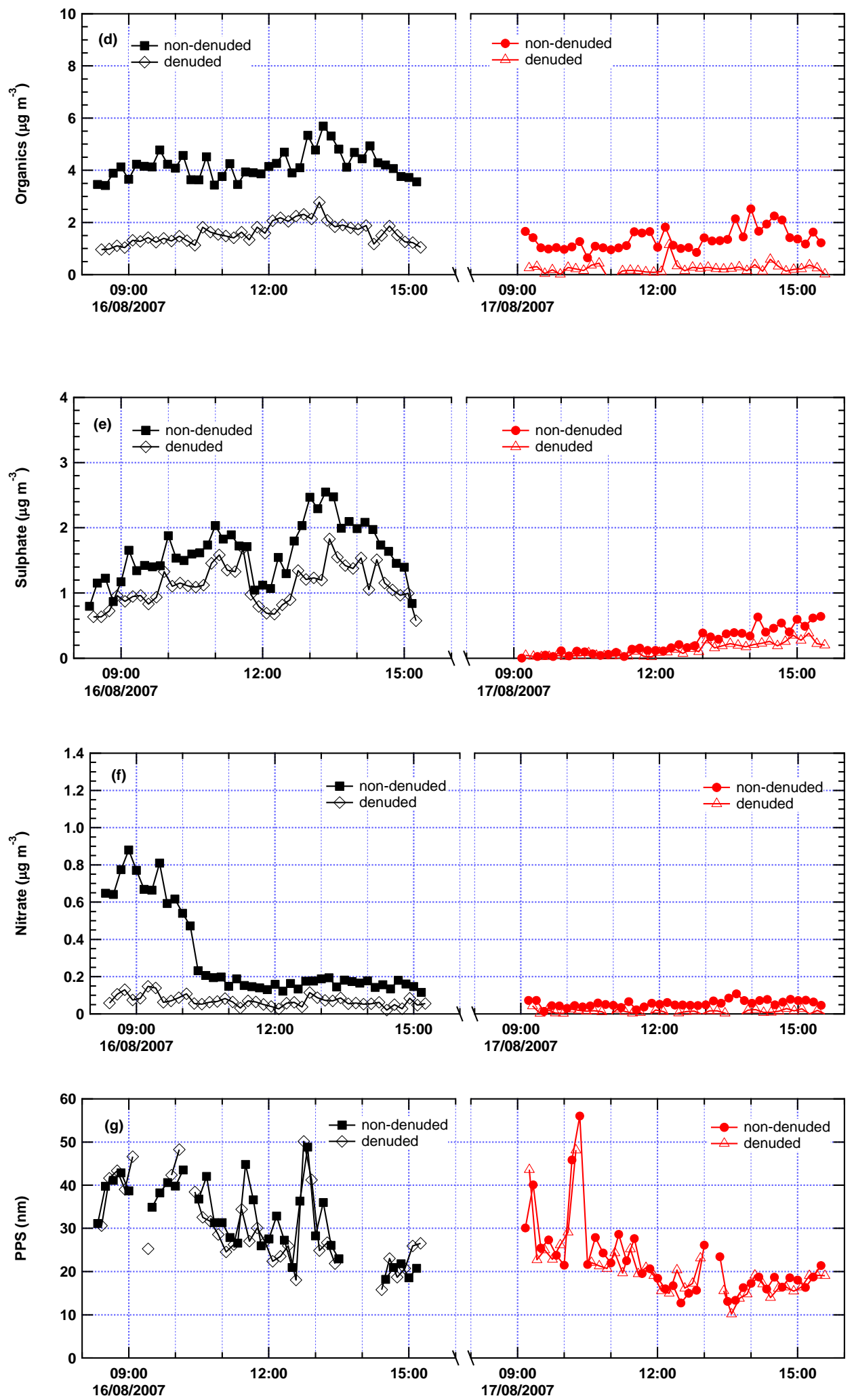

Fig. 3. Continued. 
the difference between the non-denuded and denuded SAC is variable, which is likely due to the rapid changes in the characteristics of the airmass during the initial mixing of the boundary layer. While some of the rise in sulphate may have been associated with formation in the area due to photooxidation, mixing of air containing regional sulphate from aloft likely played a role. These two processes would have altered the characteristics of the local BC particles differently. New sulphate formation due to photochemistry would have a greater potential to lead to condensation on the existing $\mathrm{BC}$, while mixing from aloft would mean that the sulphate is externally mixed with the original local BC particles. Indeed the sharp decrease and rise in sulphate from 11:30 to 13:00 indicates a variable airmass with a greater likelihood of producing an external mixture. Thus, while the thermodenuder was removing $0.5-1 \mu \mathrm{g} \mathrm{m}^{-3}$ of sulphate during the period, which is more than the amount of nitrate that was removed in the morning, the changes in SAC in time (i.e. with increasing sulphate) and between non-denuded and denuded measurements tended to be smaller than in the morning and certainly less consistent. This behaviour suggests that the sulphate on the 16th was largely externally mixed with the locally emitted BC particles and had little impact on the SAC due to much less $B C$ associated with the regional sulphate. The behaviour in the afternoon, when sulphate is high and variable, and SAC and its differences are relatively steady, yet the non-refractory mass to $\mathrm{BC}$ mass ratio is increasing, further suggests an external mixing situation.

In contrast to the 16th, the nature of the sulphate increase and its impact on SAC appears to be different on the second day. Firstly, the concentration is considerably smaller and the changes are not as sharp with the main pattern being the gradual rise in the afternoon. Focusing on the non-denuded SAC measurements (Fig. 3c), it can be seen that SAC is, despite the fluctuations, increasing slowly over this time. This is correlated with the gradual increase in non-refractory to $\mathrm{BC}$ mass ratio (Fig. 3b) and an increase in the difference between the non-denuded and denuded values. This difference is highly variable and some of it is potentially real, however the uncertainties are expected to be greater due to the low concentrations. Nonetheless, there does appear to be a pattern of an increase in the difference with a peak between 14:00 and 15:00, the same time the non-refractory mass to BC mass ratio peaks. This is also the largest hourly difference in SAC observed during the two days. Altogether, the pattern suggests that a greater portion of the non-refractory mass measured by the AMS in the afternoon of the 17th was present on the BC particles (i.e. coating). In other words, on the second day, internally mixed conditions were more prevalent. Thus, despite the low concentrations, the gradual rise in sulphate and organic matter in the afternoon was associated with local photochemical formation and condensation on the existing BC particles leading to a rise in the SAC.

Local photochemical production and downward mixing of a regional airmass would have influenced the organics
(Fig. 3d) and their impact on the non-refractory mass to BC mass ratio and on SAC in a similar manner as sulphate. In addition, a significant amount of organics is of primary origin and was likely co-emitted with $\mathrm{BC}$ in the form of internally mixed particles. This is likely the reason the variations in organics observed during the two days differs from sulphate. Interestingly, the variations in organics also appear to differ considerably from the changes in BC (Fig. 3a), as well. Thus, organics tend to have their own behaviour, but overall, the main feature with the organics is the relative lack of variability compared to the other measurements. As indicated above, there was a small rise in organic matter in the early afternoon of the 16th, corresponding with the peak in sulphate and the hypothesized mixing of a regional airmass containing higher particle mass concentrations. This organic rise is likely associated with secondary organic species not linked to the local $\mathrm{BC}$ particles (i.e. externally mixed).

Most of the time on both days the organics did not vary much making it difficult to assess how their presence affected the SAC. However, careful examination of short term fluctuations suggests there was correspondence to the BC fluctuations. For example, organics increased at the same time as the sharp peak in BC around 10:30 on the 16th. This organics increase appears to be minimal, but it was about $0.9 \mu \mathrm{g} \mathrm{m}^{-3}$, which is consistent with the $\mathrm{BC}$ increase at this time of $0.18 \mu \mathrm{g} \mathrm{m}^{-3}$ (i.e. the OC:EC ratio is reasonable). Peaks in $\mathrm{BC}$ and organics also coincide at 12:50 on the 16th and at various time points in the afternoon of the 17th. These correlations indicate that a fraction of the organics was consistently internally mixed with the $\mathrm{BC}$ particles implying that a portion of the change in SAC from non-denuded to denuded measurements was due to removal of organics. However, given the myriad of other organic particle sources in cities (e.g. cooking, evaporation and oxidation of volatile and semi-volatile organics) and contributions from the regional background airmass it is difficult to apportion the organics according to what fraction was internally mixed with the BC particles.

Lack of a change in the non-denuded SAC with changes in the non-refractory mass to $\mathrm{BC}$ mass ratio may not be entirely due to the non-refractory mass changes being associated with externally mixed particles. Another factor to consider is that this additional non-refractory mass causes structural changes to the soot aggregate such that the light absorption enhancement by the increased coating is offset by the collapse of the aggregate. Huang et al. (1994) showed that this process occurs. However, it is not possible to undertake a direct assessment of morphological changes with the current measurements. The PPS is hypothesized to change with soot aggregate collapse, varying from relatively small values associated with fresh emissions to large values when the aggregate collapses. However, during the Toronto measurements the PPS generally ranged from $20 \mathrm{~nm}$ to $60 \mathrm{~nm}$, which corresponds to the sizes associated with fresh gasoline engine and diesel engine emissions, respectively (see Fig. S2 in 
the Supplement). This is demonstrated by the peaks in BC at about 10:45, 11:30 and 12:50 on the 16th and 10:15 on the 17th, which correspond to PPS increases from less than $30 \mathrm{~nm}$ to near $50 \mathrm{~nm}$. The location of the thermodenuder experiment was in the vicinity $(\sim 75 \mathrm{~m})$ of the local building's shipping and receiving garage, which is periodically visited by diesel trucks during each day. Some of these trucks may quickly pass within $\sim 20 \mathrm{~m}$ of CRUISER. Thus, it does not appear that the PPS measurements during the thermodenuder experiment are able to provide insight related to aggregate collapse. However, the PPS measurements do provide information on the relative importance of diesel and gasoline engine emissions. In relative terms, on the 16 th there was a greater contribution from diesel vehicles compared to the 17 th because the overall PPS values on the 17th were smaller, suggesting limited influence from diesel engines throughout the day.

Fluctuations in PPS provide some indication of changes in the type of particles in the airmass being measured. Not surprisingly, from 11:00 to 15:00 on the 16th the PPS was highly variable, ranging from $20-50 \mathrm{~nm}$. In contrast, on the second day, despite the peak at about 10:15, which is due to impact from a local emission source, the PPS was relatively constant from 09:15 to 11:30 and from 12:00 to 15:00. Thus, as was inferred above, the source of the $\mathrm{BC}$ particles was relatively stable during those periods and changes in the non-refractory mass to $\mathrm{BC}$ mass ratio were due to increased vertical mixing of the local airmass and secondary sulphate and organics condensing on the $\mathrm{BC}$ particles with no significant addition of different $\mathrm{BC}$ particles from a regional airmass.

\subsection{Deployment of CRUISER to multiple locations in southern Ontario}

\subsubsection{Air quality comparison among different sites}

Table 1 summarizes the common parameters measured at the various sampling locations and/or times; these include the particle light absorption coefficient $\left(B_{\text {abs }}\right.$ ) measured from the PA, the primary particle size (PPS) and soot volume fraction (SVF) determined from the LII, the calculated BC mass concentration based on the SVF measurements, and the nonrefractory mass estimated from the AMS. Also included are the breakdowns of the mass concentrations for the four major particle components (organics, sulphate, ammonium, and nitrate) for the different data sets. Table 1 also includes the calculated specific absorption cross-section (SAC) and the non-refractory mass to $\mathrm{BC}$ mass ratios for the sites.

The highest BC concentrations, as inferred from the SVF, were observed in the Ottawa street canyon $\left(1.7 \mu \mathrm{g} \mathrm{m}^{-3}\right)$ followed by the highway in Ottawa $\left(0.58 \mu \mathrm{g} \mathrm{m}^{-3}\right)$. The lowest levels occurred in Toronto during the second day of thermodenuder experiments $\left(0.1 \mu \mathrm{g} \mathrm{m}^{-3}\right)$. Interestingly, with the exception of these three locations, correspondence between $B_{\mathrm{abs}}$ and SVF is not consistent. As shown in Sect. 3.1.3 above, the different trends in the $B_{\text {abs }}$ and SVF, indicated by the relationship between SAC and the non-refractory mass to $\mathrm{BC}$ mass ratio is related, at least partly, to the mixing state of the particles.

As expected, the measurement locations and time periods included in this study experienced different meteorological conditions and atmospheric processes. This is reflected by the overall non-refractory mass as well as the percentage of sulphate to the non-refractory mass. The particles at the Ottawa street canyon site were expected to be the least photochemically processed due to the time of measurement and the high local emissions (early morning rush hour). Consistent with this, they contained the least amount of sulphate relative to the total non-refractory mass $(7.3 \%)$ and a higher fraction of organic matter, some of which would be related to the local combustion and other local sources. Over time, due to photochemical processing in the atmosphere, more organic matter, sulphate and ammonium can form on pre-existing particles causing their relative percentages to increase. Similarly, ammonium nitrate can condense on the pre-existing particles. However, organic matter and sulphate can also increase due to airmass changes. This occurs most dramatically when regional and local airmasses mix increasing the percentage of or impact from processed particles when the regional air is relatively enriched in concentrations. In this situation, additional coating on the locally emitted particles is less likely, while externally-mixed conditions are more likely, as was exemplified above from the thermodenuder experiment.

Overall, the mass ratio of sulphate to non-refractory mass for Windsor is close to $30 \%$, suggesting the particles tended to be the most processed. However, given the relatively urban location of most of these measurements, local and regional airmass mixing was still expected. The situation in Toronto was more complicated. For example, during the 16th the site experienced an aged regional air mass and the high time resolution measurements revealed that the site encountered an externally mixed situation (see Sect. 3.1.3 and Fig. 3). As a result, the substantial increase in non-refractory mass to $\mathrm{BC}$ mass ratio did not result in a significant increase in the SAC (see Table 1) because a large fraction of the nonrefractory mass was present in particles with no $\mathrm{BC}$, rather than coated on the $\mathrm{BC}$ particles, which tend to be dominated by local emissions. These observations were discussed in detail above.

Comparing the average PPS values for the Toronto and Ottawa sites, it is clear that gasoline vehicle emissions were the dominant source of BC particles in the Toronto area while in the two Ottawa sites diesel emissions played a more important role. The averaged PPS value for the Windsor data was the largest suggesting the BC particles were mostly collapsed and heavily processed. This is consistent with the high sulphate mass present in the particles. 
Table 1. Average values for various measure quantities presented in this work. Standard deviations and the number of valid data points are included in brackets. The particle light absorption coefficient $\left(B_{\mathrm{abs}}\right)$ is measured from the photoacoustic spectrometer (PA). The primary particle size (PPS) and soot volume fraction (SVF) are obtained with the laser-induced incandescence instrument (LII). The black carbon mass concentration is calculated based on the SVF. The non-refractory mass and the breakdown of the average mass concentrations of the four major particle components are based on measurements from the Aerosol Mass Spectrometer (AMS). Specific absorption cross-section (SAC) for the period/location of interest is calculated based on the ratio of the averages of the $B_{\text {abs }}$ and SVF measurements. Corresponding uncertainties are propagated from errors from $B_{\mathrm{abs}}$ and SVF measurements. The non-refractory mass to BC mass is the ratio between the average value of non-refractory mass and the $\mathrm{BC}$ mass. The data resolution indicates the time resolution of the AMS data which the PA and LII measurements have been averaged to match accordingly. The Toronto data presented here are from the measurements obtained when the denuder was bypassed.

\begin{tabular}{|c|c|c|c|c|c|c|}
\hline \multirow[b]{2}{*}{ Inst. } & \multirow[b]{2}{*}{ Measure quantity } & \multicolumn{5}{|c|}{ Site location } \\
\hline & & $\begin{array}{l}\text { Toronto } 16 \text { Aug } \\
\text { (suburban) }\end{array}$ & $\begin{array}{l}\text { Toronto } 17 \text { Aug } \\
\text { (suburban) }\end{array}$ & $\begin{array}{l}\text { Ottawa } \\
\text { (street canyon) }\end{array}$ & $\begin{array}{l}\text { Ottawa } \\
\text { (near highway) }\end{array}$ & $\begin{array}{l}\text { Windsor } \\
\text { (in/out of city) }\end{array}$ \\
\hline $\mathrm{PA}$ & $\begin{array}{l}B_{\mathrm{abs}} \\
(\mathrm{M} \mathrm{m})^{-1}\end{array}$ & $\begin{array}{l}6.0 \\
(\mathrm{SD}=2.9, N=42)\end{array}$ & $\begin{array}{l}3.0 \\
(\mathrm{SD}=1.7, N=39)\end{array}$ & $\begin{array}{l}26 \\
(\mathrm{SD}=17, N=27)\end{array}$ & $\begin{array}{l}5.3 \\
(\mathrm{SD}=4.3, N=22)\end{array}$ & $\begin{array}{l}4.4 \\
(\mathrm{SD}=2.9, N=1137)\end{array}$ \\
\hline LII & $\begin{array}{l}\text { PPS } \\
(\mathrm{nm})\end{array}$ & $\begin{array}{l}32 \\
(\mathrm{SD}=8, N=34)\end{array}$ & $\begin{array}{l}22 \\
(\mathrm{SD}=9, N=38)\end{array}$ & $\begin{array}{l}51 \\
(\mathrm{SD}=4, N=28)\end{array}$ & $\begin{array}{l}67 \\
(\mathrm{SD}=7, N=23)\end{array}$ & $\begin{array}{l}74 \\
(\mathrm{SD}=13, N=1183)\end{array}$ \\
\hline LII & $\begin{array}{l}\text { SVF } \\
\text { (ppt) }\end{array}$ & $\begin{array}{l}0.073 \\
(\mathrm{SD}=0.031, N=34)\end{array}$ & $\begin{array}{l}0.052 \\
(\mathrm{SD}=0.029, N=38)\end{array}$ & $\begin{array}{l}0.91 \\
(\mathrm{SD}=0.45, N=28)\end{array}$ & $\begin{array}{l}0.31 \\
(\mathrm{SD}=0.13, N=23)\end{array}$ & $\begin{array}{l}0.14 \\
(\mathrm{SD}=0.12, N=1183)\end{array}$ \\
\hline LII & $\begin{array}{l}\mathrm{BC} \\
\left.(\mu \mathrm{g} \mathrm{m})^{-3}\right)\end{array}$ & $\begin{array}{l}0.14 \\
(\mathrm{SD}=0.06, N=34)\end{array}$ & $\begin{array}{l}0.10 \\
(\mathrm{SD}=0.06, N=38)\end{array}$ & $\begin{array}{l}1.7 \\
(\mathrm{SD}=0.9, N=28)\end{array}$ & $\begin{array}{l}0.58 \\
(\mathrm{SD}=0.25, N=23)\end{array}$ & $\begin{array}{l}0.27 \\
(\mathrm{SD}=0.23, N=1183)\end{array}$ \\
\hline AMS & $\begin{array}{l}\text { Non-ref. mass ( } \mu \mathrm{g} \\
\left.\mathrm{m}^{-3}\right)\end{array}$ & $\begin{array}{l}7.3 \\
(\mathrm{SD}=1.0, N=42)\end{array}$ & $\begin{array}{l}1.9 \\
(\mathrm{SD}=0.6, N=39)\end{array}$ & $\begin{array}{l}12 \\
(\mathrm{SD}=3, N=28)\end{array}$ & $\begin{array}{l}13 \\
(\mathrm{SD}=2, N=28)\end{array}$ & $\begin{array}{l}9.8 \\
(\mathrm{SD}=7.3, N=1187)\end{array}$ \\
\hline AMS & $\begin{array}{l}\text { Organics } \\
\left(\mu \mathrm{g} \mathrm{m}^{-3}\right)\end{array}$ & $\begin{array}{l}4.2 \\
(\mathrm{SD}=0.5, N=42)\end{array}$ & $\begin{array}{l}1.4 \\
(\mathrm{SD}=0.4, N=39)\end{array}$ & $\begin{array}{l}10 \\
(\mathrm{SD}=3, N=28)\end{array}$ & $\begin{array}{l}11 \\
(\mathrm{SD}=2, N=28)\end{array}$ & $\begin{array}{l}5.1 \\
(\mathrm{SD}=2.3, N=1187)\end{array}$ \\
\hline AMS & $\begin{array}{l}\text { Sulphate } \\
\left(\mu \mathrm{g} \mathrm{m}^{-3}\right)\end{array}$ & $\begin{array}{l}1.6 \\
(\mathrm{SD}=0.4, N=42)\end{array}$ & $\begin{array}{l}0.24 \\
(\mathrm{SD}=0.2, N=39)\end{array}$ & $\begin{array}{l}0.88 \\
(\mathrm{SD}=0.17, N=28)\end{array}$ & $\begin{array}{l}1.1 \\
(\mathrm{SD}=0.2, N=28)\end{array}$ & $\begin{array}{l}2.9 \\
(\mathrm{SD}=4.0, N=1187)\end{array}$ \\
\hline AMS & $\begin{array}{l}\text { Ammonium } \\
\left(\mu \mathrm{g} \mathrm{m}^{-3}\right)\end{array}$ & $\begin{array}{l}1.2 \\
(\mathrm{SD}=0.2, N=42)\end{array}$ & $\begin{array}{l}0.055 \\
(\mathrm{SD}=0.018, N=39)\end{array}$ & $\begin{array}{l}0.49 \\
(\mathrm{SD}=0.09, N=28)\end{array}$ & $\begin{array}{l}0.62 \\
(\mathrm{SD}=0.13, N=28)\end{array}$ & $\begin{array}{l}1.3 \\
(\mathrm{SD}=1.6, N=1187)\end{array}$ \\
\hline AMS & $\begin{array}{l}\text { Nitrate } \\
\left(\mu \mathrm{g} \mathrm{m}^{-3}\right)\end{array}$ & $\begin{array}{l}0.31 \\
(\mathrm{SD}=0.24, N=42)\end{array}$ & $\begin{array}{l}0.23 \\
(\mathrm{SD}=0.12, N=39)\end{array}$ & $\begin{array}{l}0.38 \\
(\mathrm{SD}=0.07, N=28)\end{array}$ & $\begin{array}{l}0.32 \\
(\mathrm{SD}=0.06, N=28)\end{array}$ & $\begin{array}{l}0.48 \\
(\mathrm{SD}=0.51, N=1187)\end{array}$ \\
\hline PA/LII & $\begin{array}{l}\text { SAC } \\
\left(\mathrm{m}^{2} \mathrm{~g}^{-1}\right)\end{array}$ & $42.9 \pm 4.3$ & $30.0 \pm 4.0$ & $15.3 \pm 2.5$ & $9.1 \pm 1.8$ & $16.3 \pm 0.7$ \\
\hline AMS/LII & $\begin{array}{l}\text { Non-ref. to BC ra- } \\
\text { tio }\end{array}$ & $52.1 \pm 3.9$ & $19.0 \pm 2.1$ & $7.1 \pm 0.8$ & $22.4 \pm 2.0$ & $36.3 \pm 1.6$ \\
\hline AMS & $\begin{array}{l}\text { Data res. } \\
(\mathrm{min})\end{array}$ & 5 & 5 & 5 & 5 & $5,10,15$ \\
\hline
\end{tabular}

\subsubsection{Comparison of the observed SAC and previous literature values}

The average SAC values for Toronto, Ottawa, and Windsor shown in Table 1 varied considerably across sites, from about $9 \mathrm{~m}^{2} \mathrm{~g}^{-1}$ at the Ottawa site to over $40 \mathrm{~m}^{2} \mathrm{~g}^{-1}$ for the Toronto site. However, one should consider that the Toronto and Ottawa data sets represent a short period of time from 2 to $6 \mathrm{~h}$ and thus may not be representative of the typical conditions in these locations. To provide some perspective on our SAC estimates a list of values reported in the literature for atmospheric particle measurements is provided in Table 2. In general, the range of average values observed in this study is within the range of the previously reported work although our measurements in Toronto are consistently near the upper end of the range.

It is important to note that there are some fundamental differences in the measurements reported from this study compared to the literature results, namely the data time resolution and the definition of BC. Most of the measurements reported in this study correspond to a time resolution as short as 15 min whereas many of the literature reported measurements were based on integrated filter measurements over a much longer period of time. High time resolution measurements have the advantage of capturing changes in atmospheric conditions that are highly dynamic (e.g. during an episode or 
Table 2. Previous reported ranges of SAC values measured for atmospheric particles.

\begin{tabular}{|c|c|c|c|c|}
\hline $\begin{array}{l}\text { SAC range } \\
\left(\mathrm{m}^{2} \mathrm{~g}^{-1}\right)\end{array}$ & Reference & Absorption method & EC definition & Notes \\
\hline $7-40$ & Sharma et al. (2004) & Aethalometer $(880 \mathrm{~nm})$ & Cachier et al. (1989) & \\
\hline $5-20$ & Liousse et al. (1993) & Aethalometer $(880 \mathrm{~nm})$ & Cachier et al. (1989) & \\
\hline $5-19$ & Martins et al. (1998) & Various & Cachier et al. (1989) & \\
\hline 9.3 & Lavanchy et al. (1999) & Aethalometer $(820 \mathrm{~nm})$ & Cachier et al. (1989) & \\
\hline 7 & Kuhlbusch (1995) & & Cachier et al. (1989) & \\
\hline $6-28$ & Sharma et al. (2002) & Aethalometer $(880 \mathrm{~nm})$ & Cachier/IMPROVE & \\
\hline $3-12$ & Sharma et al. (2002) & PSAP $(565 \mathrm{~nm})$ & Cachier/IMPROVE & \\
\hline $9-13$ & Chou et al. (2005) & Laser transmission method & IMPROVE & \\
\hline $2-6$ & Chan et al. (2010) & $\operatorname{PSAP}(567 \mathrm{~nm})$ & Huang et al. (2006) & $\begin{array}{l}\text { Analysis of SRM } \\
\text { urban dust samples } \\
\text { show similar EC } \\
\text { compared to } \\
\text { IMPROVE (Yang et al } \\
\text { 2011) }\end{array}$ \\
\hline $17-35$ & Snyder and Schauer (2007) & $\begin{array}{l}18.5 \text { at } 880 \mathrm{~nm} ; \mathrm{SAC}=35 \text { at } \\
370 \mathrm{~nm} \text { to } 17 \text { at } 950 \mathrm{~nm}\end{array}$ & NIOSH 5040 & \\
\hline $6-55$ & Jeong et al. (2004) & Aethalometer $(820 \mathrm{~nm})$ & NIOSH 5040 & \\
\hline $5-37$ & Cheng et al. (2009) & $\begin{array}{l}\text { Photoacoustic } \\
\text { Spectrometer }(532 \mathrm{~nm})\end{array}$ & NIOSH 5040 & $\begin{array}{l}\text { Relatively recent } \\
\text { results also based upon } \\
\text { more time-resolved } \\
\text { SAC measurements }\end{array}$ \\
\hline $5-25$ & Quinn et al. (2004) & $\operatorname{PSAP}(550 \mathrm{~nm})$ & NIOSH 5040 & \\
\hline $9-10$ & Knox et al. (2009) & $\begin{array}{l}\text { Photoacoustic } \\
\text { Spectrometer }(781 \mathrm{~nm})^{*}\end{array}$ & & \\
\hline $19-20$ & Knox et al. (2009) & Aethalometer $(880 \mathrm{~nm})$ & NIOSH 5040 & \\
\hline $50-53$ & Knox et al. (2009) & Aethalometer $(370 \mathrm{~nm})$ & NIOSH 5040 & \\
\hline $3-9$ & Huebert et al. (2003) & & NIOSH 5040 & \\
\hline $9-43$ & This work & $\begin{array}{l}\text { Photoacoustic } \\
\text { Spectrometer }(781 \mathrm{~nm})\end{array}$ & LII & $\begin{array}{l}\text { LII BC compares close } \\
\text { to } 1: 1 \text { with BC from } \\
\text { NIOSH } 5040\end{array}$ \\
\hline $8-10$ & Jennings and Pinnick (1980) & $550 \mathrm{~nm}$ & $\begin{array}{l}\text { Calculated based on } \\
\text { density of } 2 \mathrm{~g} \mathrm{~cm}^{-3}\end{array}$ & \\
\hline $11-12$ & Japar et al. (1986) & $\begin{array}{l}\text { Transmission method } \\
(650 \mathrm{~nm})\end{array}$ & Huntzicker et al. (1982) & \\
\hline $8-19$ & Petzold et al. (1997) & $\begin{array}{l}\text { Laser transmission method } \\
(760 \mathrm{~nm})\end{array}$ & $\begin{array}{l}\text { Other (Petzold and } \\
\text { Niessner 1995) }\end{array}$ & \\
\hline
\end{tabular}

* Wavelength indicated in the original document $(760 \mathrm{~nm})$ was incorrect.

during impact by a plume or during a brief meteorological event). Thus, they have the potential to uncover relatively short-lived higher SAC values, which are not detected due to time-averaging during the more-commonly-used integrated sampling for BC quantification.

The more-common or traditional filter measurements of $\mathrm{BC}$ are based upon the thermal/optical method to quantify elemental carbon mass concentration, such as the two step thermal method from Cachier et al. (1989), NIOSH 5040 (Birch and Cary, 1996), and IMPROVE (Chow et al., 1993). These methods typically result in different values for EC mass from the same sample because of different operating principles. For example, analysis of over 40 samples of the SRM
8785 urban dust standard reference material showed that EC mass concentration determined through the IMPROVE method can be higher by about $60-70 \%$ when compared to the NIOSH 5040 method (Yang et al., 2011). Therefore, the calculated SAC will vary considerably depending upon the method used for EC determination. For each entry in Table 2 the method used by the authors is specified.

Previous work has shown that the $\mathrm{BC}$ mass concentration measured with LII compared well with the EC mass concentration defined by the NIOSH 5040 method (McEwen et al., 2011a, b; Smallwood, 2009). This led to an overall SAC range of $9-43 \mathrm{~m}^{2} \mathrm{~g}^{-1}$ for this study (Table 2). However, if the LII values for $\mathrm{BC}$ are adjusted to be more consistent with the 
IMPROVE EC definition (i.e. assuming the IMPROVE EC is greater than the NIOSH EC by $60 \%$ ), then the SAC range for this study reduces to 6-27 $\mathrm{m}^{2} \mathrm{~g}^{-1}$ As shown in Table 2, these adjusted SAC results are consistent with the literature results based upon IMPROVE BC measurements and the measurements recorded in Toronto fit well within the range.

\subsubsection{BAQS-Met field study}

In situations when the light absorption by a $\mathrm{BC}$ particle is enhanced due to factors such as coating a higher value is inferred for the SAC using the PA and LII in parallel. The BAQS-Met data set covers a relatively large variety of scenarios and thus provides a good opportunity to explore the impact of different atmospheric processes and sources on the observed SAC. For this reason those measurements were inspected and examples were identified that illustrate a couple of unique scenarios during which the PA and LII ran concurrently along with the AMS. In this section, the relationship between SAC and other measured quantities, such as non-refractory mass to BC mass ratio and PPS are discussed for measurements on 21 June 2007, which involved changes between internally and externally mixed situations and between contributions from different particle sources. Then an example from 25 June is selected to illustrate how BC particle characteristics vary across space and time in a rural area impacted by urban outflow and lake breezes.

\section{Case 1: BC particles from different sources with different amounts of processing}

A time series of the $\mathrm{BC}$ mass concentration (measured by the LII), SAC, non-refractory mass to BC mass ratio, and PPS on 21 June from midnight to noon are shown in the panels in Fig. 4. On this day, CRUISER was parked at the West Windsor Water Pollution Control Plant connected to an external source of power (Fig. S4 in the Supplement). To the west and southwest of this location there are number industries, with a few in Windsor and more across the Detroit River. The largest facility is a steel mill located on Zug Island. There is also a coal fired power plant just to the south of the mill. The average values of most quantities measured during this period were similar to the grand averages for the entire Windsor data set (Table 1) except that the BC mass concentration was about twice as large $\left(B_{\mathrm{abs}}=8.9(\mathrm{M} \mathrm{m})^{-1}\right.$, $\mathrm{BC}=0.50 \mu \mathrm{g} \mathrm{m}^{-3}$ ) and the non-refractory mass to $\mathrm{BC}$ mass ratio was smaller at about 30 . Additional pollutant measurements, sulphate, $\mathrm{SO}_{2}, \mathrm{O}_{3}$, and $\mathrm{CO}$, together with the wind direction and wind speed from midnight to noon of this day are shown in Fig. S5 in the Supplement.

From midnight to about 02:10 the average wind direction was from the $\mathrm{W}\left(275^{\circ}\right)$ and the wind speed was $1.9 \mathrm{~m} \mathrm{~s}^{-1}$. Temperature and relative humidity were stable at $23^{\circ} \mathrm{C}$ and $44 \%$, respectively. The organic matter mass concentration (not shown) was stable with some variations. Sulphate and ammonium (not shown) were slightly elevated during the period from 00:30 to 01:30. SAC (Fig. 4b) showed a sudden drop from $22 \mathrm{~m}^{2} \mathrm{~g}^{-1}$ to $15 \mathrm{~m}^{2} \mathrm{~g}^{-1}$ at about 01:00 but generally showed no specific trend. The small drop in SAC appears to correlate weakly with a small drop in ammonium (not shown) at a similar time. During this period the PPS value (Fig. 4d) was quite stable at around $78 \mathrm{~nm}$ suggesting there were no new $\mathrm{BC}$ particles introduced into the airmass affecting the site and the existing particles were experiencing minimal in-situ processing.

Over the period from 02:10 to 07:00, the meteorology was more complicated and Fig. S4 in the Supplement provides a visual of how the different wind directions mentioned below relate to the steel mill, the coal fired power plant and the location of CRUISER. At 02:30, the wind direction shifted from $\mathrm{W}\left(275^{\circ}\right)$ to $\mathrm{SW}\left(238^{\circ}\right)$ and stayed in this direction until 03:20. After that, the wind changed rapidly to the WNW $\left(305^{\circ}\right)$ and maintained this direction from 04:00 to 04:30. Then the wind direction changed back to SW $\left(237^{\circ}\right)$ by $04: 40$ and over the period from 04:40 to 07:00 the wind direction changed slowly and gradually from SW $\left(237^{\circ}\right)$ to $\mathrm{W}\left(270^{\circ}\right)$. The significance of the period from 03:30 to 04:40 is that the wind direction swept across the steel mill and the wind speed also increased significantly and peaked at over $6 \mathrm{~m} \mathrm{~s}^{-1}$ at $04: 15$. This increased the potential for a relatively fresh pollution plume from the mill to impact upon our measurements. In the discussion below, this period is denoted as the "sweep" period (03:30-04:30). As will be shown below, the data obtained over the sweep period showed some interesting relationships when compared to measurements acquired over other selected periods.

In this section, three different periods are selected to explore further; 04:40-05:30 (period 1); 06:00-06:40 (period 2); 09:50-10:05 (period 3). For clarity these periods are shaded in orange, red, and blue in Fig. 4. During period 1 , a positive relationship is seen between the SAC and the non-refractory mass to $\mathrm{BC}$ mass ratio, but it appears not to be the case for period 2. Figure 4e illustrates this. All data points in this figure are color coded to match the temporal position in Fig. 4a-d. The observed SAC value ranges from 10 to $30 \mathrm{~m}^{2} \mathrm{~g}^{-1}$ and the overall average of these data points is $18.9 \mathrm{~m}^{2} \mathrm{~g}^{-1}$. Measurements within periods 1 and 2 are mostly in red. In addition, data points for period 1 and period 2 have the "-" and "+" symbols, respectively, on the data points. The period 1 data have a positive trend fitting with the bulk of the other points that have an increasing SAC with an increasing non-refractory mass to $\mathrm{BC}$ mass ratio in panel (e). However, for period 2 (+ points) there is a slightly negative trend or no trend and these points have an abnormally high non-refractory mass to $\mathrm{BC}$ mass ratio for the SAC observed. Comparing the meteorological measurements during these periods shows that these differences appear to relate to a mixture of different particle sources and potentially different amounts of atmospheric processing. 

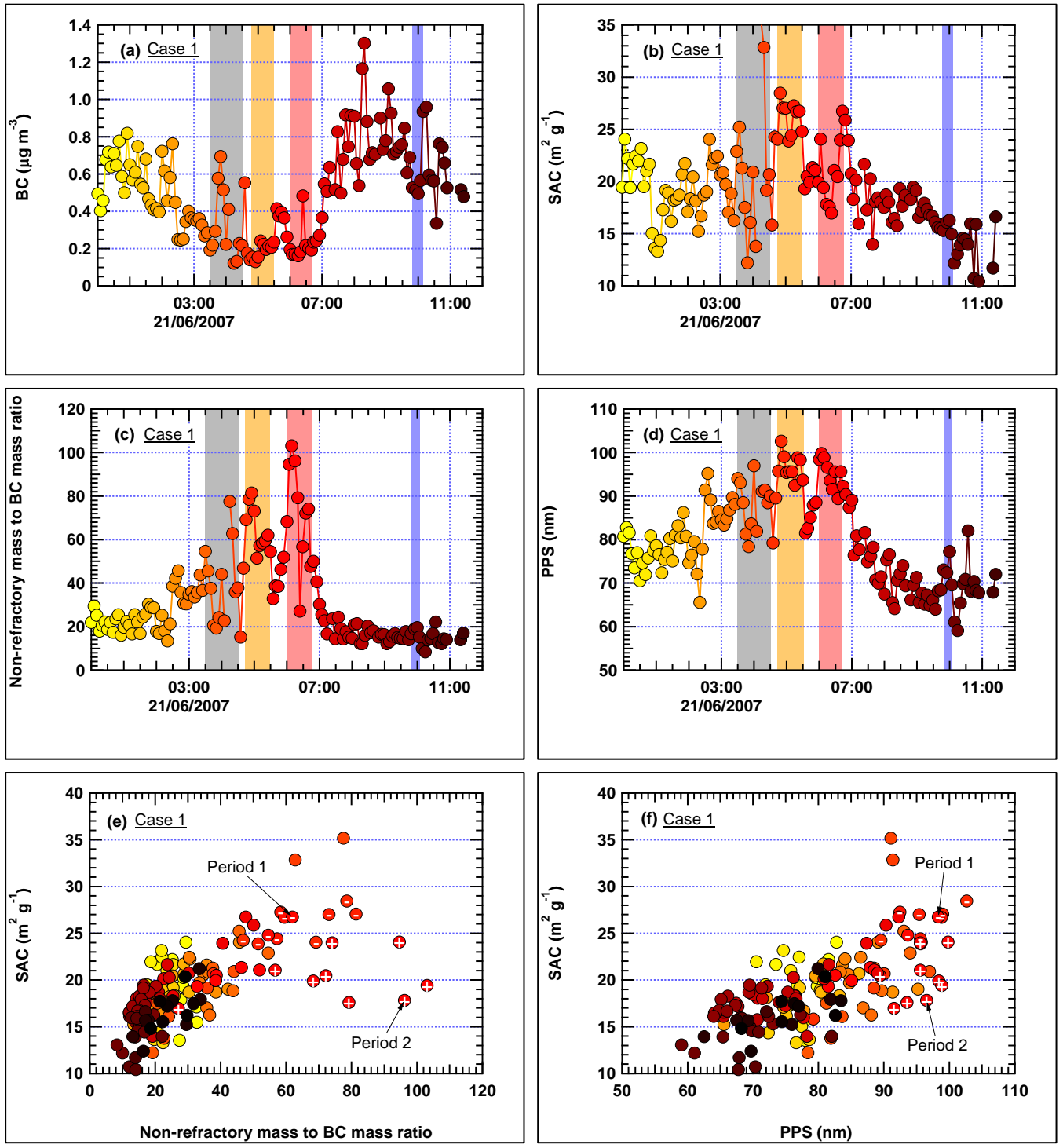

Fig. 4. Time series of five minute average (a) black carbon mass concentration, (b) SAC, (c) non-refractory mass to BC mass ratio, and (d) PPS for 21 June 2007, during the BAQS-Met study. The shaded regions of grey, orange, red, and blue represent the sweep period (03:3004:30), period 1 (04:40-05:30), period 2 (06:00-06:40), and period 3 (09:50-10:05), respectively. Relationship between the SAC and the non-refractory mass to BC mass ratio is shown in panel (e) while relationship with PPS is shown in panel (f). Data points in panels (e) and (f) are colored according to the temporal position indicated in panel (a-d). The data points with the "-" and "+" symbols represent the measurements during period 1 and 2, respectively.

Figure S4 in the Supplement shows the wind direction and speed information through a polar plot. The center of the polar plot represents the location of the CRUISER during these measurements. Each ring increment corresponds to an increase in wind speed of $2 \mathrm{~m} \mathrm{~s}^{-1}$. For period 1 (orange points), the average wind speed, wind direction, temperature, and relative humidity were $1.0 \mathrm{~m} \mathrm{~s}^{-1}$, SW $\left(232^{\circ}\right), 20.2^{\circ} \mathrm{C}$, and $71.0 \%$, respectively. For period 2 (red points), they were $1.7 \mathrm{~m} \mathrm{~s}^{-1}$, WSW $\left(255^{\circ}\right), 20.6^{\circ} \mathrm{C}$, and $64.5 \%$, respectively. For period 3 (blue points), they are $4.2 \mathrm{~m} \mathrm{~s}^{-1}$, WNW $\left(287^{\circ}\right)$, $25.5^{\circ} \mathrm{C}$, and $52.4 \%$, respectively. Thus, in these examples, the particles observed during the three periods are likely to represent a combination of different sources plus different amounts of atmospheric processing.

In period $1 \mathrm{BC}$ is low $\left(0.15-0.25 \mu \mathrm{g} \mathrm{m}^{-3}\right.$ with an increasing trend), the non-refractory mass to $\mathrm{BC}$ mass ratio is relatively high (60-80, but with an opposite decreasing trend), the PPS is large (90-100 nm and also decreasing) and the SAC is large $\left(24-28 \mathrm{~m}^{2} \mathrm{~g}^{-1}\right)$. These features are consistent with more aged particles. Given the light wind and its more southerly direction and low BC they are most likely representative of the local background particles. Their increasing 
SAC with increasing non-refractory mass to $\mathrm{BC}$ mass ratio ( - points in panel e) also suggests they are internally mixed. In period $2 \mathrm{BC}$ is also low $\left(\sim 0.2 \mu \mathrm{g} \mathrm{m}^{-3}\right)$ as in period 1 , but the non-refractory mass to $\mathrm{BC}$ mass ratio is much more variable and at times much larger than period 1 (maximum of 100). Similarly, the SAC is quite variable, but tends to be smaller than period $1\left(\sim 20 \mathrm{~m}^{2} \mathrm{~g}^{-1}\right)$. PPS is generally in the same range as period 1, although there are some smaller values. As noted above, the key difference for the data points in period 2 (+ points in panel e) is that they are not consistent with all the other points with SAC being too small for the values of the non-refractory mass to $\mathrm{BC}$ mass ratio. This strongly suggests that other particles higher in non-refractory mass are mixed with the background air during period 2 .

Concentration measurements on CRUISER provide additional insight. Sulphate and $\mathrm{SO}_{2}$ were twice as high in period 2 than in period 1 (Fig. S5). They peaked at near $6 \mu \mathrm{g} \mathrm{m}^{-3}$ and $12 \mathrm{ppb}$ in period 2 while they tended to be at the background levels observed during that night in period $1\left(2 \mu \mathrm{g} \mathrm{m}^{-3}\right.$ and $\left.4 \mathrm{ppb}\right)$. Thus, during period 2 a local source had an impact. While the winds (Fig. S4) do point towards the steel mill or perhaps the coal fired power plant power plant, the $\mathrm{CO}$ measurements strongly implicate the power plant since they did not change in this plume (200$250 \mathrm{ppb}$ ). In contrast, as will be discussed below, when the steel mill did have an impact the $\mathrm{CO}$ measurements increased dramatically (3000-5000 ppb). Thus, period 2 points do not fit with the other measurements in Fig. $4 \mathrm{e}$ because a significant amount of sulphate particles without BC led to a pronounced externally mixed situation. The fact that $\mathrm{BC}$ and PPS were quite similar between periods 1 and 2 indicates that in both cases the local background air was the source of the $\mathrm{BC}$ and only the second period had externally mixed coal fired power plant particles as well. Further LII is insensitive to particles with no $\mathrm{BC}$ content and therefore the externally mixed sulphate particles had no impact on the BC and PPS measurements.

In Fig. 5, the SAC and non-refractory mass to $\mathrm{BC}$ mass ratio for the measurements obtained over periods 1 and 2 are summarized. Also included in the plot are the data obtained during period 3 and the sweep period (shaded in grey in Fig. 4). Before discussing Fig. 5, we expand upon the observations during this period. As noted above, the wind increased in speed dramatically during the sweep period and veered from SW to NW, remained NW and relatively strong for $70 \mathrm{~min}$ and then shifted abruptly back to $\mathrm{SW}$ and became light. This is indicative of a temporary break up of the nocturnal boundary layer when the momentum from stronger winds aloft decoupled from the surface mixes down, as do other features of this air aloft, including the pollutants. Ozone measurements support this explanation. They were $\sim 20 \mathrm{ppb}$ before the sweep period, $\sim 50 \mathrm{ppb}$ during the period of maximum wind speed and back to $\sim 35 \mathrm{ppb}$ after that. The particles in this airmass originating aloft can be expected to be relatively aged. This is because their origin is linked to con-

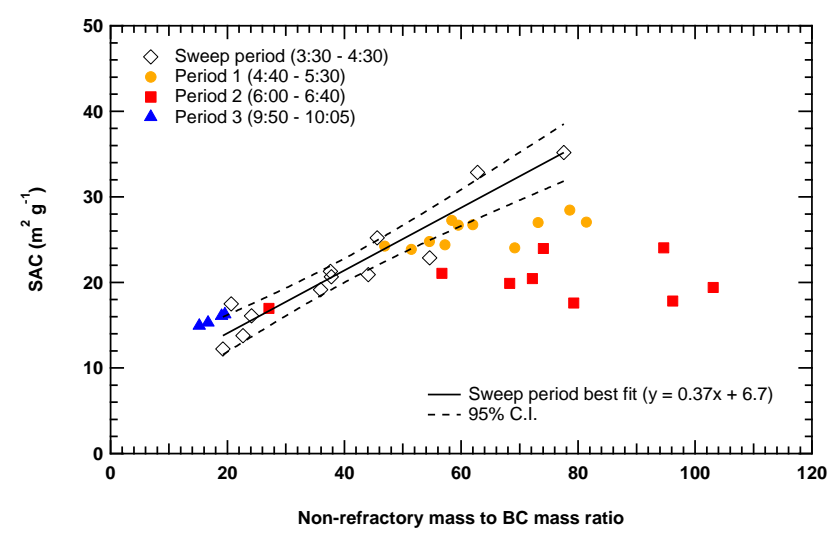

Fig. 5. Relationship between $\mathrm{SAC}$ and the non-refractory mass to BC mass ratio for four different periods observed on 21 June 2007, during the BAQS-Met field study. The open black diamonds represent the sweep period when the BC particles were mainly in an internally mixed condition. Some of these open diamond points are directly from the steel mill, while others (at higher SAC) are associated with more-aged internally mixed particles brought to the surface due to break up of the nocturnal boundary layer. Period 1 (orange circles), 2 (red squares), and 3 (blue triangles) represent different periods when other local airmasses were impacting the site. The straight line represents a linear regression fit for the black open diamonds while the dashed lines represent the $95 \%$ confident intervals.

ditions during the previous day. When the nocturnal boundary sets up and the sun sets they are preserved aloft, aging further while moving with the direction of the synoptic winds (NW).

The characteristics of the particles during this downward mixing are shown in Fig. 4 to be consistent with being aged. First of note is that the two largest SAC values during the whole night and morning ( 33 and $35 \mathrm{~m}^{2} \mathrm{~g}^{-1}$ ) were during the middle of the sweep period when winds were steady from the NW and near $7 \mathrm{~m} \mathrm{~s}^{-1}$. Focusing just on this part of the period (i.e. steady winds from the NW, which is the last half of the grey shaded area), Fig. 4 shows that BC was low at $0.1-0.2 \mu \mathrm{g} \mathrm{m}^{-3}$ and PPS was around $90-95 \mathrm{~nm}$. These values are indicative of more aged particles. The SAC and non-refractory mass to $\mathrm{BC}$ mass ratio were highly variable, reflecting the more turbulent conditions associated with the mixing during that time coupled with the low $\mathrm{BC}$ concentrations. The fact that the two points with the largest SAC values fall on the line in Fig. 4e suggest they are internally mixed, which is as would be expected for aged regional particles.

The first part of the sweep period has other interesting features that are linked to brief plumes from the steel mill. The first was for approximately 10 min near 03:40, again very briefly at 03:50 and then later when the period was ending at near 04:40. The first more prolonged period is related to the high BC concentrations shown in Fig. 4a at the start of the grey shaded section with three points around $0.6 \mu \mathrm{g} \mathrm{m}^{-3}$. As 
expected for fresher BC, the PPS dropped to $80 \mathrm{~nm}$. A close look at Fig. 4a shows that after these three points BC dropped to $0.2 \mu \mathrm{g} \mathrm{m}^{-3}$ and rose again to $0.4 \mu \mathrm{g} \mathrm{m}^{-3}$. PPS varied correspondingly with a rise to $98 \mathrm{~nm}$ and a drop to $80 \mathrm{~nm}$ for the next measurement. This brief peak in $\mathrm{BC}$ and minimum in PPS represents a second encounter with the plume. In the interval around 03:40-03:50, $\mathrm{SO}_{2}$ peaked at $40 \mathrm{ppb}$ and $\mathrm{CO}$ peaked at $>2000 \mathrm{ppb}$ (note: it may have been higher but an automatic zero occurred during this time). After these two peaks the regional background particles from above the nocturnal boundary layer prevailed, as described above. When the wind direction shifted back again at the end of the sweep period it can be seen on Fig. 4a and d that BC and PPS were briefly at $0.6 \mu \mathrm{g} \mathrm{m}^{-3}$ and $80 \mathrm{~nm}$, respectively. While those values are similar to the plume at the start of the sweep period and $\mathrm{CO}$ peaked at $5000 \mathrm{ppm}, \mathrm{SO}_{2}$ only had a small peak at $8 \mathrm{ppb}$. Not surprisingly, the SAC $\left(15 \mathrm{~m}^{2} \mathrm{~g}^{-1}\right)$ and the nonrefractory mass to $\mathrm{BC}$ mass ratio (20) during these short impacts by the plume from the steel mill were both lower than what was observed in the regional background air.

Returning to Fig. 5 and focusing on the measurements obtained during the sweep period (black open diamonds) reveals a nearly linear relationship. This suggests that both the $\mathrm{BC}$ particles in the regional background air and the $\mathrm{BC}$ particles from the steel mill were similarly internally mixed with the non-refractory mass that was present. This internally mixed assumption is made based on the high positive relationship between the SAC and the non-refractory mass to $\mathrm{BC}$ mass ratio $\left(R^{2}=0.91\right)$. However, also note that in a highly homogeneous scenario, it is possible to have a situation with a relatively small but constant amount of externally mixed particles present that also impact upon the measurements, similar to a dilution situation. This would also be expected to yield a straight slope, but with a potentially smaller gradient. Nonetheless, the observed particles that were related to the steel mill appear in the lower left of Fig. 5 because they were fresher with less non-refractory mass (i.e. less coating). It should be noted that when these particles were observed there would still have been the background particles present, but the BC from the steel mill likely dominated the signals detected by the PA and LII given the increase in BC seen in Fig. 4a.

The regression line is shown on Fig. 5 to highlight the relationship between the mostly internally-mixed points measured during the sweep period and to help differentiate them from measurements points obtained during different periods. However, while this line is not expected to represent a universal relationship between coating and SAC, it is interesting to note that given its magnitude the $\mathrm{y}$-intercept may have a significant meaning. It could suggest that for these BC particles, which are likely from different origins (i.e. some from the regional background above Detroit and others from the steel mill), the SAC value would be $6.7 \mathrm{~m}^{2} \mathrm{~g}^{-1}$ if the particles were not coated (i.e. contained no non-refractory material). This value is similar in magnitude to the suggested value of
$5 \mathrm{~m}^{2} \mathrm{~g}^{-1}$ given by Fuller et al. (1999) for isolated spheres of typical diesel soot. This value is also highly consistent with the value of $6.8 \mathrm{~m}^{2} \mathrm{~g}^{-1}$ estimated by Hitzenberger (1999) based on comparison between laboratory generated pure BC particles measured from an Aethalometer and the integrating sphere technique using thermal $\mathrm{EC}$ as the reference.

The measurements obtained during period 3 (blue triangles) are near the line associated with the data from the sweep period, but at the low end. This is not surprising as Fig. 4(a) shows that during period 3 the $\mathrm{BC}$ levels were similar to measurements during the sweep period when the steel mill plume was observed. However, the SAC and PPS values were lower than the sweep period values. This could be meteorologically driven in that this was at 10:00 when the boundary layer was breaking up (wind speed was 4-5 $\mathrm{m} \mathrm{s}^{-1}$ ) and thus, a different proportion of steel mill and regional background particles could have occurred. RH was lower at this time as well, at $52.4 \%$. Also, this is near the end of rush hour so some of these fresh BC particles may have been from traffic or local diesel equipment operating during the day at the steel mill. Nonetheless, the period 3 particles fit on the line and are likely fresh and internally mixed. There are four orange points (period 1) on Fig. 5 that do not fit near the line, but behave more like the period 2 points. Closer look at period 1 shows that each of these points fell within a 20 min stretch at the start of period 1 when the coal fired power plant had an impact. Sulphate had a peak at about $5 \mu \mathrm{g} \mathrm{m}^{-3}$ and $\mathrm{SO}_{2}$ peaked at $8 \mathrm{ppb}$, while there was no corresponding rise in $\mathrm{CO}$ (Fig. S5). Thus, these four points also represent an externally mixed situation.

\section{Case 2: variations in regional background air and the urban plume}

The mobility of CRUISER enabled relatively quick changes in measurement location in order to sample particles expected to exhibit different characteristics. On 25 June 2007, in the morning, there was a light SW wind flow over southwestern Ontario, which was eventually modified by lake breeze circulations induced by Lakes St. Clair and Erie (Sills et al., 2011). CRUISER was deployed to three locations: $75 \mathrm{~km}$ due east of downtown Windsor/Detroit at a rural location (Fletcher-FL); $75 \mathrm{~km}$ NE next to the shore of Lake St. Clair (Mitchell's Bay-MB); and $75 \mathrm{~km} \mathrm{NNE}$ at a rural location (Bear Creek-BCr). Other papers in the "The Border Air Quality and Meteorology Study (BAQS-Met) special issue" (2010) include maps of the region (e.g. Levy et al., 2010) and show the location of $\mathrm{BCr}$ relative to Lake St. Clair and Windsor/Detroit. CRUISER's driving route involved multiple visits to FL and $\mathrm{MB}$ as it was hypothesized that MB was in the urban plume while FL was more likely experiencing regional background air. $\mathrm{BCr}$ was also expected to be in the urban plume. The order of visits and arrival times were: FL1 (10:10) - MB1 (11:00) - FL2 (11:45) -MB2 (12:35) - FL3 (13:50) - FL4 (14:45) - BCr (16:30). At each of 
these locations, during which stops ranged from 10 to $30 \mathrm{~min}$, wind speed and direction were monitored along with LII, PA, AMS and gaseous pollutant measurements. Table S1 in the Supplement summarizes selected key measurements at each location/time. Figure 6 is an expanded version of Fig. 5 to include points for each of these visits.

For the first visit to Fletcher (FL1) the site was in an airmass representative of the rural background over southern Ontario $(\mathrm{CO}=182 \mathrm{ppb})$. The relatively light $\mathrm{SW}$ winds $\left(1.3 \mathrm{~m} \mathrm{~s}^{-1}\right)$ and the position of Fletcher between the Lake St. Clair and Lake Erie lake breeze fronts indicate that the observations at this time were representative of the airmass residing over land and downwind of more populated regions after atmospheric processing overnight and recent break up of the nocturnal boundary layer. Consistent with this situation, the SAC was consistently large at $25 \mathrm{~m}^{2} \mathrm{~g}^{-1}$ (Fig. 6). However, this point is on the right of the regression line determined from the sweep period on 21 June, indicating that the non-refractory mass to $\mathrm{BC}$ mass ratio was relatively large and there were potentially also particles containing non-refractory mass externally mixed with the dominant BC particles.

Approximately $50 \mathrm{~min}$ later CRUISER was at MB1 and $\mathrm{CO}$ was higher at $262 \mathrm{ppb}$, indicating the expected influence from upwind urban emissions. Winds were from the $\mathrm{SW}$ in the general direction of the Windsor/Detroit area. The SAC at this time was $14 \mathrm{~m}^{2} \mathrm{~g}^{-1}$, consistent with fresher BC particles compared to the previous measurements at FL1. The non refractory mass to $\mathrm{BC}$ mass ratio of MB1 was slightly larger than observed at FL1, and thus even more suggestive of externally mixed particles with significant non-refractory mass. Figure 6 shows that the BC particles at FL2 during next set of measurements $(\sim 1.5 \mathrm{~h}$ after the first visit) had a smaller SAC compared to FL1, but a larger non-refractory mass to $\mathrm{BC}$ mass ratio. In addition, both of these parameters were more variable, as indicated by the error bars on the figure. Clearly, the airmass at Fletcher had changed between the first two visits with fresher $\mathrm{BC}$ particles and a greater contribution from other regional particles (i.e. particles with high non-refractory mass and low/negligible $\mathrm{BC}$ ) during the second visit.

A closer look at the individual wind direction and speed measurements during FL2 helps explain the large variability in the SAC and non-refractory mass to $\mathrm{BC}$ mass ratio. The lake breeze frontal zone, associated with Lake Erie, was actually right in the vicinity of FL at this time. This caused the winds to be gusty and to fluctuate between SW and SE. This gusty behaviour, which is indicative of vertical mixing, typically enhanced at the front (Sills et al., 2011; Hayden et al., 2011), was serving to rapidly change airmasses, leading to a variety of particles being observed on CRUISER in a short time: $\mathrm{BC}$ particles, from the most aged air drawn down from aloft in the gusts $\left(\mathrm{SAC} \sim 30 \mathrm{~m}^{2} \mathrm{~g}^{-1}\right.$; PPS $>82 \mathrm{~nm}$ ); very fresh particles ( $\mathrm{SAC}<10 \mathrm{~m}^{2} \mathrm{~g}^{-1} ;$ PPS $\sim 67 \mathrm{~nm}$ ) potentially a result of CRUISER's own emissions (i.e. the diesel gener-

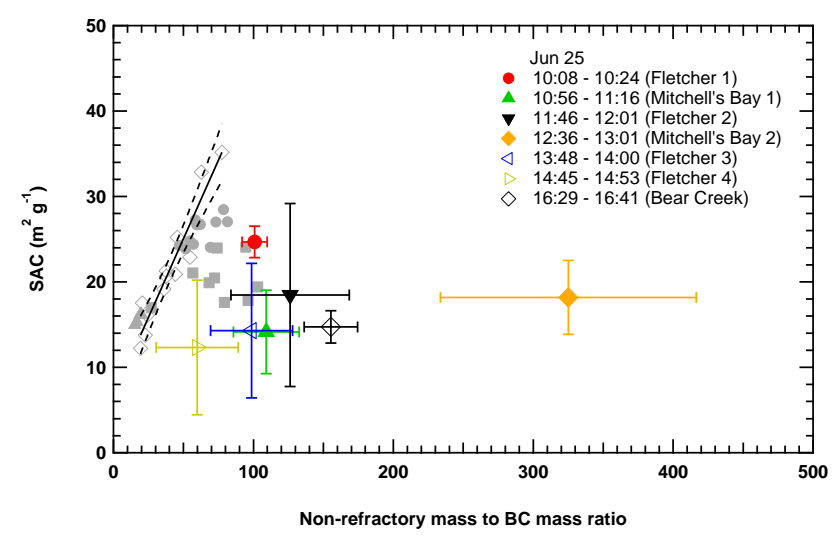

Fig. 6. Relationship between SAC and the non-refractory mass to BC mass ratio for various locations (Fletcher, Mitchell's Bay, Bear Creek) in southern Ontario on 25 June 2007, during the mobile deployment of CRUISER. The different measurement locations (Fletcher, Mitchell's Bay or Bear Creek) and times are represented by different markers. All grey markers are the data points in the original Fig. 5. The black solid and dashed lines represent the regression best fit and $95 \%$ confidence interval fit of the data points of the sweep period on 21 June.

ator emissions were difficult to keep downwind due to the highly turbulent winds); and moderately aged particles associated with air behind the Lake Erie front $\left(\mathrm{SAC} \sim 14 \mathrm{~m}^{2} \mathrm{~g}^{-1}\right.$; PPS $\sim 79 \mathrm{~nm}$ ).

MB2 remained under a SW wind flow when CRUISER returned at 12:35. The winds were stronger suggesting that the lake breeze had intensified, which complicates determination of the origin of the airmass. However, $\mathrm{CO}$ was still indicative of urban influence ( $275 \mathrm{ppb})$. Figure 6 shows that the SAC had increased slightly from the first visit $\left(18 \mathrm{~m}^{2} \mathrm{~g}^{-1}\right)$ and interestingly the non-refractory mass to $\mathrm{BC}$ mass ratio was much larger. At this time $\mathrm{SO}_{2}$ was $48 \mathrm{ppb}$ and sulphate was $24 \mu \mathrm{g} \mathrm{m}^{-3}$, indicative of a relatively fresh industrial plume. $\mathrm{BC}$ concentration was half of the value observed during the first visit ( $\left.0.14 \mathrm{vs.} 0.28 \mu \mathrm{g} \mathrm{m}^{-3}\right)$ and thus, particles in this $\mathrm{SO}_{2}$ plume consisted predominantly of non-refractory mass that were externally mixed with the urban-related $\mathrm{BC}$ particles, which is clearly reflected by the large distance to the right of the regression line in Fig. 6. Thus, despite this large amount of non-refractory mass, it had little influence on SAC.

For the next two visits to FL (FL3 and FL4) this site was under SE winds since the lake breeze front from Lake Erie had moved north of the site. The airmass sampled was relatively clean with steadily decreasing non-refractory mass concentrations as the air from Lake Erie became entrenched over the area. However, the lake breeze frontal zone was not far to the north and this continued to cause variability in $\mathrm{SAC}$ and the non-refractory mass to $\mathrm{BC}$ mass ratio, as was observed during FL2. However, on average, the BC particles observed in FL3 and FL4 tended to be fresher and likely 
of more local origin. The trend in Fig. 6 reflects these conditions with decreasing values for the mean non-refractory mass to $\mathrm{BC}$ mass ratio and mean $\mathrm{SAC}$, but with wide error bars due to the frontal mixing zone nearby.

The last measurements obtained by CRUISER were taken $1 \mathrm{~h} 45 \mathrm{~min}$ later and $40 \mathrm{~km}$ north of Fletcher at Bear Creek $(\mathrm{BCr})$. Wind direction $(\mathrm{SW})$ and speed $\left(2.5 \mathrm{~m} \mathrm{~s}^{-1}\right)$ at this location indicate that CRUISER was back in the airmass associated with a breeze from Lake St. Clair, likely containing particles related to emissions in Windsor/Detroit although the lower $\mathrm{CO}$ concentration indicates that this airmass was more dispersed $\left(\mathrm{CO}=191 ; \mathrm{BC}=0.2 \mu \mathrm{g} \mathrm{m}^{-3}\right)$. The $\mathrm{SAC}$ $\left(15 \mathrm{~m}^{2} \mathrm{~g}^{-1}\right)$ value in Fig. 6 suggests that the BC particles were of similar age and origin as those observed at MB, especially during the first visit. Overall, the three SAC measurements downwind of Windsor/Detroit (at MB1, MB2, and $\mathrm{BCr}$ ) were similar $\left(14-18 \mathrm{~m}^{2} \mathrm{~g}^{-1}\right)$. However, these values were closer to the fresher BC particles seen in Windsor on 21 June, than to the particles seen relatively nearby at FL1 $\left(\mathrm{SAC}=25 \mathrm{~m}^{2} \mathrm{~g}^{-1}\right)$ during the first visit.

The 25 June case shows that in the countryside $75 \mathrm{~km}$ (or $\sim 7-11 \mathrm{~h}$ ) downwind of large cities reasonably homogeneous airmasses with similar BC particles do occur and can be located, but that it is also possible for relatively large changes in SAC to occur over short periods of time and/or distances. Detailed knowledge of airmass history is required to be able to interpret these patterns, particularly in regions with complex meteorology such as the Great Lakes region of southern Ontario. In the next section, all of the SAC measurements obtained in this study are compared to provide an indication of the range observed during CRUISER's various deployments.

\section{SAC versus non-refractory mass to $\mathrm{BC}$ mass ratio across different sites}

Measurements in this study demonstrate not only that, as would be expected, there is an observable positive relationship between SAC and the non-refractory mass to BC mass ratio, but that there are periods when this relationship is difficult to observe due to more complex particle mixtures (i.e. external mixtures). In these cases, there is an apparent lack of the expected relationship, as highlighted by some of the observations in Figs. 5 and 6. While each individual particle in such airmasses would be expected to follow this relationship up to a certain BC particle size and coating thickness (i.e. based upon theory in Bond et al., 2006), when ensemble measurements are made, even over time periods as short as those used for PA and LII allowed (1-5 min), the variability in the net light absorbing behaviour of the collection of particles suspended in the air is highly complex. However, the case studies above show that with detailed information this variability can be interpreted, providing insight. Nonetheless, the degree of variability indicated by the results above show that within urban and rural southern Ontario it is diffi- cult to predict, in detail, what the SAC value will be, given known amounts of $\mathrm{BC}$, organics, sulphate, etc. The mixing state of these particle constituents also needs to be known. Predictions will also be difficult in other regions where there is a considerable amount of emissions of particles that are evolving and mixing with regional background air.

Figures 5 and 6 show, however, that there may still be some general patterns in how SAC varies that can provide some useful insight such as upper and lower bounds on SAC and when conditions might favour lower vs. higher values. Consequently, Fig. 7 compares the relationship between SAC and the non-refractory mass to $\mathrm{BC}$ mass ratio across all the different measurement locations and times included in this study. Each measurement point in Fig. 7 represents the average value over a 30 -min time interval, which was selected to further reduce measurement noise. Given the complexity observed over the shorter time steps, the 30 min interval was expected to adequately portray meaningful averages associated with the same airmass. Collectively, all the data show that as the ratio in non-refractory mass to $\mathrm{BC}$ mass increases the SAC increases and that $30 \mathrm{~min}$ SAC ranges from near $9 \pm 2$ to $43 \pm 4 \mathrm{~m}^{2} \mathrm{~g}^{-1}$.

The Windsor measurements (black circles) cover the largest range of the non-refractory mass to $\mathrm{BC}$ mass ratio in Fig. 7. This is because the largest amount of data was obtained during the BAQS-Met study, which provided a greater opportunity to observe a wide range of conditions. In addition, this region of southern Ontario is most affected by large local $\mathrm{SO}_{2}$ emissions and other industries and experiences a higher regional background of sulphate and organics, which is typified by more-processed particles. It should be noted that since all the data are combined in Fig. 7, differing degrees of externally mixed situations are lumped together. However, as Figs. 3-6 show, it is possible to identify measurements that are most likely influenced by externally mixed particles with relatively high concentrations of non-refractory mass and relatively low concentrations of BC. Most of the Windsor measurements with high values of nonrefractory mass to $\mathrm{BC}$ mass ratio are considerably to the right compared to the sweep period (Figs. 5 and 6). This indicates that the majority of these BC particles (as demonstrated in Sect. 3.2.3 case 2) were part of an externally mixed atmosphere. However, in general, the Windsor data show a positive trend confirming that an increase in non-refractory mass to BC mass ratio generally causes a higher SAC for the mostly collapsed particles prevalent during BAQS-Met (i.e. a large mean PPS).

The Toronto measurements (red diamonds) exhibited a similar pattern to Windsor data in that a positive relationship is observed, but the SAC values were significantly higher and mostly on the left of the sweep period (Fig. 5). There are several key differences that may have led to such an observation. The Toronto site was impacted more by recently emitted BC particles, which were likely to still have been in a more open aggregate form. The smaller PPS values observed in Toronto 


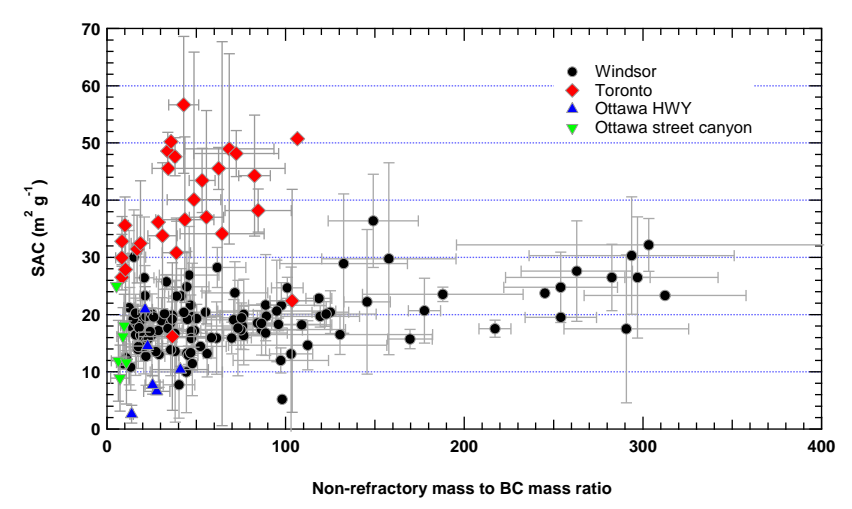

Fig. 7. Relationship between the SAC and the non-refractory mass to $\mathrm{BC}$ mass ratio for all measurements from this study. Each data point represents an average value of a $30-\mathrm{min}$ time interval. The error bars represent the standard deviation among all the measurements in the 30-min interval. The Windsor, Toronto, Ottawa highway, and Ottawa street canyon data are represented by black circles, red diamonds, blue upward triangles and green downward triangles, respectively.

(22 32 nm) support this assertion. In contrast, the mean PPS among the Windsor measurements was the largest at $74 \mathrm{~nm}$. Given that this value is beyond the PPS value of freshly emitted diesel particles shown in Fig. S2 suggests that the BC particles observed in Windsor were typically collapsed. We also hypothesize that the high SAC values for the Toronto data may be related to the combination of the small particle size and the morphology of the BC particles together with a relatively large amount of non-refractory material on the individual BC particles. Bond et al. (2006) suggested that the contribution of very small particles that have very high absorption enhancement is insignificant. However, within the complexity of the urban atmosphere, such phenomena may exist and it may only be with instruments which possess high temporal resolution that such conditions can be captured. In Fig. 7, there are two data Toronto data points that appear to be further away from the majority of the points. Closer inspection shows that the data point with a non-refractory mass to $\mathrm{BC}$ ratio of 37 was impacted by a few measurements with very fresh emissions (PPS $\sim 18 \mathrm{~nm}$ and a low SAC). The data point with a non-refractory mass to $\mathrm{BC}$ mass ratio of about 100 was caused by mixing of an aged air mass containing high non-refractory mass during which the SAC remained practically constant compared to the 30-min measurements before and after this period.

Combining the Toronto and Windsor measurements suggests that the SAC can be much larger for a given amount of potential coating when the non-refractory mass is present on more open $\mathrm{BC}$ aggregates rather than on more-spherical collapsed BC particles. In addition, the Toronto data show that the rate of increase in SAC with the non-refractory mass to $\mathrm{BC}$ mass ratio is greater for particles in the more open aggregate form. The predominance of gasoline engine $\mathrm{BC}$ particles may have played a role in the high SAC values in Toronto, however this study was not designed to explore this possibility.

The Ottawa measurements (triangles) generally fall within the Windsor data and scatter around the sweep period measurements (Fig. 5), but at the low end of the non-refractory mass to $\mathrm{BC}$ mass ratio. This is not surprising given the location and time of these measurements (i.e. close to traffic). As expected for a low ratio, the Ottawa SAC values were relatively small despite the highest $\mathrm{BC}$ mass concentrations at these two sites.

To summarize the patterns shown in Fig. 7, one hypothesis would be that a fresh BC aggregate structure alone will not have a large SAC value if the quantity of coating is relatively small. This was generally the case for Ottawa. However, once a significant amount of non-refractory material starts to collect on these aggregates there can be an observable and large increase in SAC, as seen in Toronto where the measurements were taken farther from the traffic compared to Ottawa. Over time, the BC aggregates collapse due to atmospheric processing, such as from clouds and condensation on the particles of water or of organic and/or inorganic material. With these more-aged collapsed particles, which were most prevalent in and around Windsor during BAQS-Met, additional non-refractory material condensing or forming on them still results an increase in SAC. However, due to the higher degree of externally mixed conditions for these scenarios, the rate of increase in SAC versus the non-refractory mass to $\mathrm{BC}$ mass ratio is smaller.

\section{Conclusions}

A thermodenuder was used at an urban site to study the effect of volatile and semi-volatile particle coating mass on fine $\mathrm{BC}$ particles using photoacoustic spectrometer (PA) and laserinduced incandescence (LII) instruments. Results show that the black carbon (BC) measurements obtained from the LII are independent of the non-refractory mass on the particles, whereas the $\mathrm{BC}$ mass concentration inferred through the PA can be enhanced by the presence of the non-refractory mass on the particles. This indicated that the auto-compensating high sensitivity LII is an appropriate technique for the measurement of atmospheric BC mass concentrations. Furthermore, the use of real time PPS measurements from the LII provides the possibility for identifying the influence of fresh emissions from gasoline and diesel exhaust versus aged BC particles.

The combination of simultaneous LII and PA measurements resulted in an in-situ measure of the time-resolved specific absorption cross-section (SAC), a new capability previously unreported, and provides information that is not available using traditional longer time integrated measurements of BC. Ambient measurements at four different locations 
show that the SAC for ambient particle is highly variable. In areas where $\mathrm{BC}$ particles tend to be more aged and hence the $\mathrm{BC}$ structure is collapsed and coated with considerable amounts of non-refractory material, such as the region in and around Windsor, an average SAC of $16 \pm 1 \mathrm{~m}^{2} \mathrm{~g}^{-1}$ was observed. In urban locations with a high contribution of gasoline vehicles and occasional impacts from regional pollution, such as Toronto, SAC values vary from $30 \pm 4 \mathrm{~m}^{2} \mathrm{~g}^{-1}$ to $43 \pm 4 \mathrm{~m}^{2} \mathrm{~g}^{-1}$. In locations with large contributions from diesel vehicles, such as the Ottawa street canyon, a SAC of $15 \pm 3 \mathrm{~m}^{2} \mathrm{~g}^{-1}$ is observed.

This study also demonstrates that ambient $\mathrm{BC}$ particle SAC values vary significantly within short time periods and/or distances. Under conditions of highly complex meteorology, such as at a lake breeze frontal zone downwind from a large urban/industrial area, the nature of the $\mathrm{BC}$ particles can fluctuate minute by minute, if not more rapidly (i.e. the PA and LII data were not examined at a higher time resolution). This clearly demonstrates that deriving SAC from longer integration time measurements, such as has been traditionally done when the $\mathrm{BC}$ is obtained through thermal/optical analysis from filters, can greatly smooth out the true variations. Thus, at best, these approaches provide a mean value for SAC. While this might be generally representative for converting $B_{\text {abs }}$ to $\mathrm{BC}$ mass, it can also lead to an attenuation or exaggeration of the true variability in $\mathrm{BC}$ mass depending upon the nature of the correlation between $B_{\mathrm{abs}}$ and SAC.

The variations in SAC observed from all measurements within this study are closely related to different BC sources (e.g. different types of engines and/or operating conditions) and meteorological conditions, which affect the type and amount of atmospheric processing. Overall, combining data from four different locations reveals that the value of the SAC is generally larger when the $\mathrm{BC}$ particles possess a significant amount of non-refractory material and particularly when they still maintain the aggregate structure. Continued increase in non-refractory material coating on the particle generally increases the SAC value. Atmospheric particles that are mostly collapsed are found further downwind of the sources and in those cases they tend to exhibit various degrees of external mixing with regional background non-BC particles. Increasing non-refractory material on these particles still produces increases SAC. However, in those cases to quantify the impact of particle coating on the light absorption by the $\mathrm{BC}$ particles, it is critical to differentiate the externally mixed non-refractory mass from the internally mixed non-refractory mass. An approach for inferring the degree of external mixing was demonstrated in this paper. This is based upon comparing individual ambient measurements of the SAC and the ratio of non-refractory mass to $\mathrm{BC}$ mass to reference ambient $\mathrm{BC}$ particle measurements derived from measurements during conditions that were dominated by internally mixed conditions.

\section{Appendix A}

\begin{tabular}{ll}
\multicolumn{2}{l}{ Notations } \\
LII & Laser induced incandescence \\
SVF & Soot volume fraction measured by LII \\
PPS & Primary particle size measured by LII \\
PA & Photoacoustic spectrometer \\
$B_{\text {abs }}$ & Light absorption coefficient measured by the PA \\
AMS & Aerosol Mass Spectrometer \\
SAC & Specific absorption cross-section \\
$\rho_{\text {soot }}$ & Material density of soot $=1.9 \mathrm{~g} \mathrm{~cm}^{-3}$ \\
FL & Fletcher, Ontario \\
MB & Mitchell's Bay, Ontario \\
BCr & Bear Creek, Ontario
\end{tabular}

\section{Supplementary material related to this article is available online at: http://www.atmos-chem-phys.net/11/10407/2011/ acp-11-10407-2011-supplement.pdf.}

Acknowledgements. The authors sincerely thank Julie Narayan and Cris Mihele for their assistance in collecting, organizing, and providing the CRUISER measurements used in this study. The authors also want to thank Peter Barton and Jacek Rostkowski for their useful discussions regarding the characteristics and operations of the gasoline and diesel powered engines. This research was supported in part by PERD Particles and Related Emission Project C11.008, PERD AFTER Project C23.006, and CCTII Project TIB6.15, which are programs administered by Natural Resources Canada. Some funding for Tak W. Chan came from Environment Canada through Natural Sciences and Engineering Research Council (NSERC) postdoctoral visiting fellowship.

Edited by: D. Hastie

\section{References}

Allan, J. D., Jimenez, J. L., Williams, P. I., Alfarra, M. R., Bower, K. N., Jayne, J. T., Coe, H., and Worsnop, D. R.: Quantitative sampling using an Aerodyne Aerosol Mass Spectrometer, 1, Techniques of Data Interpretation and Error Analysis, J. Geophys. Res., 108, 4090, doi:10.1029/2002JD002358, 2003.

Amann, C. A. and Siegla, D. C.: Diesel particulates - what they are and why, Aerosol Sci. Technol., 1, 73-101, 1982.

Arnott, W. P., Moosmüller, H., and Rogers, C. F.: Photoacoustic spectrometer for measuring light absorption by aerosol: instrument description, Atmos. Environ., 33, 2845-2852, 1999.

Birch, M. E. and Cary, R. A.: Elemental carbon-based method for monitoring occupational exposures to particulate diesel exhaust, Aerosol Sci. Technol., 25, 221-241, 1996.

Bond, T. C. and Bergstrom, R. W.: Light absorption by carbonaceous particles: an investigative review, Aerosol Sci. Technol., 40, 27-67, 2006.

Bond, T. C. and Sun, H.: Can reducing black carbon emissions counteract global warming? Environ. Sci. Technol., 39, 59215926, 2005. 
Bond, T. C., Anderson, T. L., and Campbell, D.: Calibration and intercomparison of filter based measurements of visible light absorption by aerosols, Aerosol Sci. Technol., 30, 582-600, 1999.

Bond, T. C., Habib, G., and Bergstrom, R. W.: Limitations in the enhancement of visible light absorption due to mixing state, J. Geophys. Res., 111, D20211, doi:10.1029/2006JD007315, 2006.

Bryce, D. J., Ladommatos, N., and Zhao, H.: Quantitative investigation of soot distribution by laser-induced incandescence, Appl. Optics, 39, 5012-5022, 2000.

Burtscher, H.: Physical characterization of particulate emissions from diesel engines: a review, J. Aerosol Sci., 36, 896-932, 2005.

Cachier, H., Brémond, M. P., and Buat-Ménard, P.: Determination of atmospheric soot carbon with a simple thermal method, Tellus, 41B, 379-390, 1989.

Chan, T. W., Huang, L., Leaitch, W. R., Sharma, S., Brook, J. R., Slowik, J. G., Abbatt, J. P. D., Brickell, P. C., Liggio, J., Li, S.M., and Moosmüller, H.: Observations of OM/OC and specific attenuation coefficients (SAC) in ambient fine PM at a rural site in central Ontario, Canada, Atmos. Chem. Phys., 10, 2393-2411, doi:10.5194/acp-10-2393-2010, 2010.

Cheng, Y. F., Berghof, M., Garland, R. M., Wiedensohler, A., Wehner, B., Müller, T., Su, H., Zhang, Y. H., Achtert, P., Nowak, A., Pöschl, U., Zhu, T., Hu, M., and Zeng, L. M.: Influence of soot mixing state on aerosol light absorption and single scattering albedo during air mass aging at a polluted regional site in northeastern China, J. Geophys. Res, 114, D00G10, doi:10.1029/2008JD010883, 2009.

Chou, C. C. K., Chen, W. N., Chang, S. Y., Chen, T. K., and Huang, S. H.: Specific absorption cross-section and elemental carbon content of urban aerosols, Geophys. Res. Lett., 32, L21808, doi:10.1029/2005GL024301, 2005.

Chow, J. C., Watson, J. G., Pritchett, L. C., Pierson, W. R., Frazier, C. A., and Purcell, R. G.: The DRI thermal/optical reflectance carbon analysis system: description, evaluation and applications in U.S. air quality studies, Atmos. Environ., 27A, 1185-1201, 1993.

Chow, J. C., Watson, J. G., Crow, D., Lowenthal, D. H., and Merrifield, T.: Comparison of IMPROVE and NIOSH carbon measurements, Aerosol Sci. Technol., 34, 23-34, 2001.

Dillner, A. M., Stein, C., Larson, S. M., and Hitzenberger, R.: Measuring the mass extinction efficiency of elemental carbon in rural aerosol, Aerosol Sci. Technol., 35, 1009-1021, 2001.

Faxvog, F. R. and Roessler, D. M.: Mass concentration of diesel particle emissions from photoacoustic and opacity measurements, Aerosol Sci. Technol., 1, 225-234, 1982.

Fuller, K. A., Malm, W. C., and Kreidenweis, S. M.: Effects of mixing on extinction by carbonaceous particles, J. Geophys. Res., 104, 15941-15954, 1999.

Gangl, M., Kocifaj, M., Videen, G., and Horvath, H.: Light absorption by coated nano-sized carbonaceous particles, Atmos. Environ., 42, 2571-2581, 2008.

Hallett, J., Hudson, J. G., and Rogers, C. F.: Characterization of combustion aerosols for haze and cloud formation, Aerosol Sci. Technol., 10, 70-83, 1989.

Hayden, K. L., Sills, D. M. L., Brook, J. R., Li, S.-M., Makar, P. A., Markovic, M. Z., Liu, P., Anlauf, K. G., O’Brien, J. M., Li, Q., and McLaren, R.: Aircraft study of the impact of lake-breeze circulations on trace gases and particles during BAQS-Met 2007,
Atmos. Chem. Phys., 11, 10173-10192, doi:10.5194/acp-1110173-2011, 2011.

Heywood, J. B.: Pollutant formation and control in Internal combustion engine fundamental, Ch. 11, pp. 567-660, McGraw-Hill, Inc., New York, 1988.

Hitzenberger, R., Jennings, S. G., Larson, S. M., Dillner, A., Cachier, H., Galambos, Z., Rouc, A., and Spain, T. G.: Intercomparison of measurement methods for black carbon aerosols, Atmos. Environ, 33, 2823-2833, 1999.

Horvath, H.: Atmospheric light absorption-a review, Atmos. Environ., 27A, 293-317, 1993.

Huang, L., Brook, J. R., Zhang, W., Li, S. M., Graham, L., Ernst, D., Chivulescu, A., and Lu, G.: Stable isotope measurements of carbon fractions (OC/EC) in airborne particulate: a new dimension for source characterization and apportionment, Atmos. Environ., 40, 2690-2705, 2006.

Huang, P. F., Turpin, B. J., Pipho, M. J., Kittelson, D. B., and McMurry, P. H.: Effects of water condensation and evaporation on diesel chain-agglomerate morphology, J. Aerosol Sci., 25, 447459, 1994.

Huebert, B. J., Bates, T., Russell, P. B., Shi, G., Kim, Y. J., Kawamura, K., Carmichael, G., and Nakajima, T.: An overview of ACE-Asia: strategies for quantifying the relationships between Asian aerosols and their climatic impacts, J. Geophys. Res., 108, 8633, doi:10.1029/2003JD003550, 2003.

Huntzicker, J. J., Johnson, R. L., Shah, J. J., and Cary, R. A.: Analysis of organic and elemental carbon in ambient aerosols by a thermal-optical method, in Particulate carbon - atmospheric life cycle, edited by: Wolff, G. T. and Klimisch, R. L., 79-88, Plenum Press, New York, 1982.

Iskander, M. F., Chen, H. Y., and Penner, J. E.: Resonance optical absorption by fractal agglomerates of smoke aerosols, Atmos. Environ., 25A, 2563-2569, 1991.

Japar, S. M., Brachaczek, W. W., Gorse Jr., R .A., Norbeck, J. M., and Pierson, W. R.: The contribution of elemental carbon to the optical properties of rural atmospheric aerosols, Atmos. Environ., 20, 1281-1289, 1986.

Jayne, J. T., Leard, D. C., Zhang, X., Davidovits, P., Smith, K. A., Kolb, C. E., and Worsnop, D. R.: Development of an Aerosol Mass Spectrometer for size and composition analysis of submicron particles, Aerosol Sci. Technol., 33, 49-70, 2000.

Jennings, S. G. and Pinnick, R. G.: Relationship between visible extinction absorption and mass concentration of carbonaceous smokes, Atmos. Environ., 14, 1123-1129, 1980.

Jeong, C. H., Hopke, P. K., Kim, E., and Lee, D. W.: The comparison between thermal-optical transmittance elemental carbon and Aethalometer black carbon measured at multiple monitoring sites, Atmos. Environ., 38, 5193-5204, 2004.

Jimenez, J. L., Jayne, J. T., Shi, Q., Kolb, C. E., Worsnop, D. R., Yourshaw, I., Seinfeld, J. H., Flagan, R. C., Zhang, X., Smith, K. A., Morris, J. W., and Davidovits, P.: Ambient aerosol sampling using the Aerodyne Aerosol Mass Spectrometer, J. Geophys. Res., 108, 8425, doi:10.1029/2001JD001213, 2003.

Johnson, K. S., Zuberi, B., Molina, L. T., Molina, M. J., Iedema, M. J., Cowin, J. P., Gaspar, D. J., Wang, C., and Laskin, A.: Processing of soot in an urban environment: case study from the Mexico City Metropolitan Area, Atmos. Chem. Phys., 5, 30333043, doi:10.5194/acp-5-3033-2005, 2005.

Kittelson, D. B.: Engines and nanoparticles: a review, J. Aerosol 
Sci., 29, 575-588, 1998.

Knox, A., Evans, G. J., Brook, J. R., Yao, X., Jeong, C. H., Godri, K. J., Sabaliauskas, K., and Slowik, J. G.: Mass absorption crosssection of ambient black carbon aerosol in relation to chemical age, Aerosol Sci. Technol., 43, 522-532, 2009.

Kuhlbusch, T.: Method for determining black carbon in residues of vegetation fires, Environ. Sci. Technol., 29, 2695-2702, 1995.

Lack, D. A. and Cappa, C. D.: Impact of brown and clear carbon on light absorption enhancement, single scatter albedo and absorption wavelength dependence of black carbon, Atmos. Chem. Phys., 10, 4207-4220, doi:10.5194/acp-10-4207-2010, 2010.

Lack, D. A., Lovejoy, E. R., Baynard, T., Pettersson, A., and Ravishankara, A. R.: Aerosol absorption measurement using photoacoustic spectroscopy: sensitivity, calibration, and uncertainty developments, Aerosol Sci. Technol., 40, 697-708, 2006.

Lavanchy, V. M. H., Gäggeler, H. W., Nyeki, S., and Baltensperger, U.: Elemental carbon (EC) and black carbon (BC) measurements with a thermal method and an aethalometer at the high-alpine research station Jungfraujoch, Atmos. Environ., 33, 2759-2769, 1999.

Levy, I., Makar, P. A., Sills, D., Zhang, J., Hayden, K. L., Mihele, C., Narayan, J., Moran, M. D., Sjostedt, S., and Brook, J.: Unraveling the complex local-scale flows influencing ozone patterns in the southern Great Lakes of North America, Atmos. Chem. Phys., 10, 10895-10915, doi:10.5194/acp-10-10895-2010, 2010.

Lewis, K. A., Arnott, W. P., Moosmüller, H., Chakrabarty, R. K., Carrico, C. M., Kreidenweis, S. M., Day, D. E., Malm, W. C., Laskin, A., Jimenez, J. L., Ulbrich, I. M., Huffman, J. A., Onasch, T. B., Trimborn, A., Liu, L., and Mishchenko, M. I.: Reduction in biomass burning aerosol light absorption upon humidification: roles of inorganically-induced hygroscopicity, particle collapse, and photoacoustic heat and mass transfer, Atmos. Chem. Phys., 9, 8949-8966, doi:10.5194/acp-9-8949-2009, 2009.

Liousse, C., Cachier, H., and Jennings, S. G.: Optical and thermal measurements of black carbon aerosol content in different environments: variation of the specific attenuation cross-section, Sigma, Atmos. Environ., 27A, 1203-1211, 1993.

Liu, F., Stagg, B. J., Snelling, D. R., and Smallwood, G. J.: Effects of primary particle size distribution on the temperature of soot particles heated by a nanosecond pulsed laser in an atmospheric laminar diffusion flame, International Journal of Heat and Mass Transfer, 49, 777-788, 2006.

Liu, L., Mishchenko, M. I., and Arnott, W. P.: A study of radiative properties of fractal soot aggregates using the superposition Tmatrix method, J. Quant. Spectrosc. Ra., 109, 2656-2663, 2008.

Martins, J. V., Artaxo, P., Liousse, C., Reid, J. S., Hobbs, P. V., and Kaufman, Y. J.: Effects of black carbon content, particle size, and mixing on light absorption by aerosols from biomass burning in Brazil, J. Geophys. Res., 103, 32041-32050, 1998.

McEwen, J. D. N., Johnson, M. R., and Thomson, K. A.: Experimental measurement of elemental carbon \& organic carbon for soot producing lab-scale flares, in Proceeding of Air and Waste Management Association 104th Annual Conference, 21-24 June, Orlando, FL, 2011-A-490-AWMA, 2011a.

McEwen, J. D. N., Thomson, K. A., and Johnson, M. R.: Experimental measurements of particle phase pollutants for lab scale flares in Proceeding of Combustion Institute, Canadian Section Spring Technical Meeting, 8-11 May, Winnipeg, Manitoba, Pa- per C3-1, 2011b.

Mewes, B. and Seitzman, J. M.: Soot volume fraction and particle size measurements with laser-induced incandescence, Appl. Optics, 36, 709-717, 1997.

Moosmüller, H., Chakrabarty, R. K., and Arnott, W. P.: Aerosol light absorption and its measurements: a review, J. Quant. Spectrosc. Ra., 110, 844-878, 2009.

Moteki, N. and Kondo, Y.: Effects of mixing state on black carbon measurements by laser-induced incandescence, Aerosol Sci. Technol., 41, 398-417, 2007.

Murphy, D. M.: The effect of water evaporation on photoacoustic signals in transition and molecular flow, Aerosol Sci. Technol., 43, 356-363, 2009.

Pagels, J., Khalizov, A. F., McMurry, P. H., and Zhang, R. Y.: Processing of soot by controlled sulphuric acid and water condensation - mass and mobility relationship, Aerosol Sci. Technol., 43, 629-640, 2009.

Park, K., Cao, F., Kittelson, D. B., and McMurry, P. H.: Relationship between particle mass and mobility for diesel exhaust particles, Environ. Sci. Technol., 37, 577-583, 2003.

Petzold, A., Kopp, C., and Niessner, R.: The dependence of the specific attenuation cross-section on black carbon mass fraction and particle size, Atmos. Environ., 31, 661-672, 1997.

Quinn, P. K., Coffman, D. J., Bates, T. S., Welton, E. J., Covert, D. S., Miller, T. L., Johnson, J. E., Maria, S., Russell, L., Arimoto, R., Carrico, C. M., Rood, M. J., and Anderson, J.: Aerosol optical properties measured on board the Ronald $\mathrm{H}$. Brown during ACE-Asia as a function of aerosol chemical composition and source region, J. Geophys. Res., 109, D19S01, doi:10.1029/2003JD004010, 2004.

Ramachandran, G. and Reist, P. C.: Characterization of morphological changes in agglomerates subject to condensation and evaporation using multiple fractal dimension, Aerosol Sci. Technol., 23, 431-442, 1995.

Raspet, R., Hickey, C. J., and Sabatier, J. M.: The effect of evaporation-condensation on sound progatation in cylindrical tubes using the low reduced frequency approximation, J. Acoust. Soc. Am., 105, 65-73, 1999.

Raspet, R., Slaton, W. V., Arnott, W. P., and Moosmüller, H.: Evaporation-condenation effects on resonant photoacoustic of volatile aerosols, J. Atmos. Oceanic Technol., 20, 685-695, 2003.

Schnaiter, M., Linke, C., Möhler, O., Naumann, K. H., Saathoff, H., Wagner, R., Schurath, U., and Wehner, B.: Absorption amplification of black carbon internally mixed with secondary organic aerosol, J. Geophys. Res., 110, D19204, doi:10.1029/2005JD006046, 2005.

Schulz, C., Kock, B. F., Hofmann, M., Michelsen, H., Will, S., Bougie, B., Suntz, R., and Smallwood, G.: Laser-induced incandescence: recent trends and current questions, Appl. Phys. B, 83, 333-354, 2006.

Schwarz, J. P., Gao, R. S., Fahey, D. W., Thomson, D. S., Watts, L. A., Wilson, J. C., Reeves, J. M., Darbeheshti, M., Baumgardner, D. G., Kok, G. L., Chung, S. H., Schulz, M., Hendricks, J., Lauer, A., Kärcher, B., Slowik, J. G., Rosenlof, K. H., Thompson, T. L., Langford, A. O., Loewenstein, M., and Aikin, K. C.: Single-particle measurements of midlatitude black carbon and light-scattering aerosols from the boundary layer to the lower stratosphere, J. Geophys. Res., 111, D16207, 
doi:10.1029/2006JD007076, 2006.

Schwarz, J. P., Gao, R. S., Spackman, J. R., Watts, L. A., Thomson, D. S., Fahey, D. W., Ryerson, T. B., Peischl, J., Holloway, J. S., Trainer, M., Frost, G. J., Baynard, T., Lack, D. A., de Gouw, J. A., Warneke, C., and Del Negro, L. A.: Measurement of the mixing state, mass, and optical size of individual black carbon particles in urban and biomass burning emissions, J. Geophys. Res., 35, L13810, doi:10.1029/2008GL033968, 2008.

Sharma, S., Brook, J. R., Cachier, H., Chow, J., Gaudenzi, A., and Lu, G.: Light absorption and thermal measurements of black carbon in different regions of Canada, J. Geophys. Res., 107, 4771, doi:10.1029/2002JD002496, 2002.

Sharma, S., Lavoué, D., Cachier, H., Barrie, L.A., and Gong, S.L.: Long-term trends of the black carbon concentrations in the Canadian Arctic, J. Geophys. Res., 109, D15203, doi:10.1029/2003JD004331, 2004.

Shiraiwa, M., Kondo, Y., Iwamoto, T., and Kita, K.: Amplification of light absorption of black carbon by organic coating, Aerosol Sci. Technol., 44, 46-54, 2010.

Sills, D. M. L., Brook, J. R., Levy, I., Makar, P. A., Zhang, J., and Taylor, P. A.: Lake breezes in the southern Great Lakes region and their influence during BAQS-Met 2007, Atmos. Chem. Phys., 11, 7955-7973, doi:10.5194/acp-11-7955-2011, 2011.

Slowik, J. G., Cross, E. S., Han, J. H., Davidovits, P., Onasch, T. B., Jayne, J. T., Williams, L. R., Canagaratna, M. R., Worsnop, D. R., Chakrabarty, R. K., Moosmüller, H., Arnott, W. P., Schwarz, J. P., Gao, R. S., Fahey, D. W., Kok, G. L., and Petzold, A.: An inter-comparison of instruments measuring black carbon content of soot particles, Aerosol Sci. Technol., 41, 295-314, 2007a.

Slowik, J. G., Cross, E. S., Han, J. H., Kolucki, J., Davidovits, P., Williams, L. R., Obasch, T. B., Jayne, J. T., Kolb, C. E., and Worsnop, D. R.: Measurements of morphology changes of fractal soot particles using coating and denuding experiments: implications for optical absorption and atmospheric lifetime, Aerosol Sci. Technol., 41, 734-750, 2007 b.

Smallwood, G. J.: A critique of laser-induced incandescence for the measurement of soot, Ph.D. Thesis, Cranfield University, Cranfield, UK, October, 2008.
Smallwood, G. J., Clavel, D., Gareau, D., Sawchuk, R. A., Snelling, D. R., Witze, P. O., Axelsson, B., Bachalo, W. D., and Gülder, Ö. L.: Concurrent quantitative laser-induced incandescence and SMPS measurements of EGR effect on particulate emissions from a TDI diesel engine, SAE Technical Paper, 2002-01-2715, 1-16, 2002.

Snelling, D. R., Smallwood, G. J., Campbell, I. G., Medlock, J. E., and Gülder, Ö. L.: Development and application of laser induced incandescence (LII) as a diagnostic for soot particulate measurements, AGARD Conference Proceedings 598, Advanced NonIntrusive Instrumentation for Propulsion Engines, 23-1 to 23-9, 1998.

Snelling, D. R., Smallwood, G. J., Sawchuk, R., Neill, W. S., Gareau, D., Clavel, D. J., Chippior, W., Liu, F., Gülder, Ö. L., and Bachalo, W. D.: In-situ real-time characterization of particulate emissions from a diesel engine exhaust by laser-induced incandescence, SAE Technical Paper Series, 2000-01-1994, 2000.

Snelling, D. R., Smallwood, G. J., Liu, F., Gülder, Ö. L., and Bachalo, W. D.: A calibration-independent LII technique for soot measurement by detecting absolute light intensity, Appl. Optics, 44, 6773-6785, 2005.

Snyder, D. C. and Schauer, J. J.: An inter-comparison of two black carbon aerosol instruments and a semi-continuous elemental carbon instrument in the urban environment, Aerosol Sci. Technol., 41, 463-474, 2007.

Turpin, B. J., Cary, R. A., and Huntzicker, J. J.: An in situ, time-resolved analyzer for aerosol organic and elemental carbon, Aerosol Sci. Technol., 12, 161-171, 1990.

Wainner, R. T. and Seitzman, J. M.: Soot diagnostics using laserinduced incandescence in flames and exhaust flows, AIAA paper, AIAA-99-0640, 1999.

Xue, H., Khalizov, A. F., Wang, L., Zheng, J., and Zhang, R.: Effects of dicarboxylic acid coating on the optical properties of soot, Phys. Chem. Chem. Phys., 11, 7869-7875, 2009.

Yang, F., Huang, L., Duan, F., Zhang, W., He, K., Ma, Y., Brook, J. R., Tan, J., Zhao, Q., and Cheng, Y.: Carbonaceous species in PM2.5 at a pair of rural/urban sites in Beijing, 2005-2008, Atmos. Chem. Phys., 11, 7893-7903, doi:10.5194/acp-11-78932011, 2011. 